九州大学学術情報リポジトリ

Kyushu University Institutional Repository

\title{
State of 3-D micro-damage in hydrogen redistributed regions of precharged high strength aluminium alloy
}

\section{Gupta, Chi radeep}

Department of Mechanical Engineering, Toyohashi University of Technology

Toda, Hiroyuki

Department of Mechanical Engineering, Toyohashi University of Technology

Fuj ioka, T.

Department of Mechanical Engineering, Toyohashi University of Technology

Kobayashi, Masakazu

Department of Mechanical Engineering, Toyohashi University of Technology

他

http://hdl. handle. net/2324/4150460

出版情報：Corrosion Science. 111，pp.26-38，2016-10. Elsevier バージョン：

権利関係: 
State of 3-D micro-damage in hydrogen redistributed regions of precharged high strength aluminium alloy

C. Gupta ${ }^{1, \mathrm{a}, \#}$, H. Toda ${ }^{1, \mathrm{~b}}$, T. Fujioka ${ }^{1}$, M. Kobayashi ${ }^{1}$, H. Hoshino $^{1}$, K. Uesugi ${ }^{2}$, A. Takeuchi $^{2}$, Y. Suzuki ${ }^{2}$

1: Department of Mechanical Engineering, Toyohashi University of Technology, Toyohashi, Aichi 441-8150, Japan.

2: Japan Synchrotron Radiation Institute, Sayo-Gun, Hyogo, Japan.

a: Presently at Materials Group, Bhabha Atomic Research Centre, Mumbai, India.

b: Presently at Department of Mechanical Engineering, Kyushu University, Japan.

\# : Corresponding author.

Email: joy gupta71@yahoo.co.in; cgupta@barc.gov.in

\section{Abstract}

The state of 3-D micro-damage in regions of precharged high strength aluminium alloy where hydrogen redistribution is induced by thermal treatment, or deformation near intergranular fracture surface, are compared using synchrotron microtomography (SR- $\mu \mathrm{CT})$. The mapping of various types of micro-damage provides evidence that hydrogen redistribution occurs along with a change in content and shape of micro-pores. The presence of intergranular cracks and an extended agglomerated micro-pore damage state are found to be in close proximity to each other, suggesting a mechanistic relationship for both formation of the unique damage architecture and insidious manifestation of embrittlement in high strength aluminium alloys.

Keywords : A. Aluminium alloy; B. X-ray microtomography; C. Hydrogen Embrittlement

\section{Highlights}

- Micro-damage state formed in hydrogen redistributed regions of AA 7075 is revealed.

- H-redistribution due is shown to change the content and shape of micro-pores.

- Extended agglomerated zone is revealed for the first time near intergranular crack.

- Embrittled damage state is shown increase micro-pore content for H-repartition. 


\section{Introduction}

The presence of elevated levels of hydrogen in the matrix of aluminium and its alloys is common despite its low solubility at room temperature [1]. The solubility gap of hydrogen in the liquid and solid states of aluminium facilitates the trapping of hydrogen in the matrix [1, 2]. Apart from this, ingress of hydrogen in aluminium can occur in the presence of a suitable environment such as chlorides, or even with moist air (which is exacerbated in the presence of stress) [3-5].The presence of hydrogen is known to adversely influence the structural properties of aluminium alloys [4-7]. It is a challenge to contain the debilitating effects of hydrogen in aluminium alloys due to the ubiquitous nature of its available sources. Therefore the embrittling influence of hydrogen on aluminium alloys precludes the application of high strength aluminium alloys for structural applications. The intensive research devoted towards clarifying the mechanism of hydrogen embrittlement and cracking in aluminium and its alloys are focussed on the pathways of hydrogen its ingress and its interactions with microstructure to identify the possible trapping sites in the matrix. [8-12].

It is believed that with knowledge of trapping sites after ingress, the manifestation of hydrogen embrittlement can be mitigated through alloying and heat treatment [13-18]. However it is well known that the hydrogen is no longer present at their trap sites in the matrix when either thermal cycle for desorption is given $[9,10]$ or when the aluminium alloy is deformed [19]. This implies that the atomistic interactions between hydrogen and matrix during intergranular failure do not take place at the distributed traps after ingress but at local sites such as grain boundaries. Given the limited diffusivity of hydrogen in aluminium matrix [20], it is advocated that the redistribution is facilitated by carriers of the hydrogen eg. dislocation [21, 22] or alloying elements, such as $\mathrm{Mg}$ [23]. In a recent investigation by Toda et. al. [24] using synchrotron microtomography, it is shown that in Al-Si alloy containing different levels of trapped hydrogen, the micro-pore fraction not only dramatically increases by a desorption 
treatment, but also that these micro-pores are portent equilibrium trapping sites for hydrogen in the matrix. It is also well known that prior to fracture significant localized plastic deformation occurs at regions such as, at the neck or crack tip, where damage is created.

In the context of hydrogen embrittlement, this property of the micro-pores encourages the view that hydrogen redistribution during deformation from the equilibrium trapping sites could be repartitioned at the plasticity led damage occurring in the matrix. The possibility of hydrogen repartitioning is completely ignored in the established mechanistic understanding of hydrogen embrittlement in aluminium alloys. This is because the relationship between redistributing hydrogen and the state of damage has yet to be investigated in the context of manifestation of hydrogen embrittlement. In this work the term redistribution of hydrogen refers to the migration of $\mathrm{H}$ atoms in the matrix with the aid of carriers such as vacancies, dislocations or solute atoms. The term repartition of hydrogen refers to its presence in deep traps possibly, as molecular hydrogen in micro-pores. A consequence of repartition of redistributing hydrogen to the micro-pores is to alter the damage structure in the matrix as it would promote the localisation of the degrading effects of hydrogen. This can be examined by characterizing the state of damage in terms of mapping the content, morphology and spatial distribution of micro-pores within the affected regions where hydrogen is known to have redistributed.

Thus the main motivation of the present study is to examine the state of damage in regions where hydrogen redistribution would have occurred, so that the view that the $\mathrm{H}$ repartition at these sites is clarified. Accordingly in the present investigation high resolution ( $1 \mu \mathrm{m})$ synchrotron microtomography is carried out on regions of precharged AA 7075 in the underaged condition after giving a desorption treatment, and after undergoing deformation leading to brittle tensile fracture. The unique feature of studying these two regions are that they offer comparison between hydrogen redistribution phenomenon in aluminium alloys that has 
not only vastly different fraction of equilibrium trap sites available for repartitioning but also have opposing effects on the manifestation of embrittlement.

\section{Experimental}

\subsection{Materials}

The high strength aluminium alloy selected for the studies is AA 7075. The chemical composition of the alloy is given in table 1.It was received as hot extruded rods with typical flat pancake grain structure. The material was heat treated by a solution zing step at $520^{\circ} \mathrm{C}$ for 144 hours followed by aging at $120^{\circ} \mathrm{C}$ for 8 hours in an oil bath. This long solutionsing treatment transformed the flat pancake grain structure found in the hot extruded rods of AA7075 to an equi-axed microstructure with average grain size of about $80 \mu \mathrm{m}$. Linear intercept method was used to estimate the average grain size. The studies were carried out on under-age AA7075 as this condition is known to make the alloy most susceptible to hydrogen embrittlement [25].

2.2 Methods for hydrogen charging, desorption treatment and tensile test

The electrochemical method was used to charge hydrogen in the machined tensile sample. The setup consisted of poisoned (with $\mathrm{Na}_{2} \mathrm{HAsO}_{4} \cdot 7 \mathrm{H}_{2} \mathrm{O}$ or sodium arsenate dibasic hepta hydrate) sulphuric acid of $0.5 \mathrm{M}$ strength as electrolyte at $25^{\circ} \mathrm{C}$, a fine platinum wire mesh as the anode and the tensile sample as the cathode connected to a constant DC power source by platinum wires. The samples were charged using a current density of $4000 \mathrm{~A} / \mathrm{m}^{2}$ uninterrupted for 72 hours with continuous stirring of the electrolyte. Small sample coupons were charged along with the tensile sample and analysed by vacuum fusion method to assess the total hydrogen content. It was found that the total hydrogen content increased from $0.18 \mathrm{ml} \mathrm{H} / 100$ $\mathrm{g} \mathrm{Al}$ to $0.82 \mathrm{ml} \mathrm{H} / 100 \mathrm{~g} \mathrm{Al}$ as result of the cathodic charging. One set of hydrogen charged samples-coupons were given a desorption treatment by a slow heating rate ( in the range 1- 
$2^{\circ} \mathrm{C} / \mathrm{min}$ ) from room temperature to $500^{\circ} \mathrm{C}$ where it was soaked for 4 hours. The samples were furnace cooled subsequently. Cathodic hydrogen precharging was also carried out on the tensile samples which were pulled to failure in a screw-driven universal testing machine at room temperature using a nominal strain rate of $10^{-6} \mathrm{~s}^{-1}$. The gauge dimensions of the tensile samples were $6 \mathrm{~mm}$ diameter and $30 \mathrm{~mm}$ length. These tensile tests were carried out within a few hours of the hydrogen charging test. The strain during the test was measured using a laser extensometer that scanned between two markers placed $5 \mathrm{~mm}$ apart in the central portion of gauge of the specimen, which corresponded to its viewing window. The tensile failure was brittle consisting of an intergranular fracture surface. The ductility of the hydrogen precharged sample in terms of strain to failure was about 5\%. The sample coupons extracted for tomography studies from the variously processed specimen of AA 7075 are shown in figure 1 as colour boxes. It is clear that for the present studies the tomographic scans have been carried out on initial specimen after heat treatment to achieve equiaxed structure, after cathodic hydrogen charging, after desorption treatment and finally after intergranular failure from two locations one near the outer surface and the other near the centre of the specimen. In the paper the tomographic datasets obtained for the above conditions is denoted by the nomenclature ' $\Delta_{\mathrm{j}}^{\mathrm{i}}$ ' where $\mathrm{i}=$ 'o' if there is no thermal treatment step for inducing H-desorption; ' $\mathrm{T}$ ', if desorption treatment is given and ' $\mathrm{F}$ ' if the parent sample from which the coupon is extracted was deformed to fracture; $\mathrm{j}=$ ' $\mathrm{UC}$ ' if charging is not been carried out; ' $\mathrm{C}$ ' if precharging is given; In case the coupons have to be differentiated by spatial location the nomenclature of the obtained dataset is ' $\Delta_{\mathrm{j}}^{\mathrm{i}}$ : $\mathrm{k}$ '; where $\mathrm{i}, \mathrm{j}$ have the meaning as above and $\mathrm{k}={ }^{\prime} \mathrm{C}$ ' if the coupon location is at the parent sample centre and ' $\mathrm{S}$ ' if the parent sample is near the surface region.

\subsection{Synchrotron Microtomography $(\mathrm{SR}-\mu \mathrm{CT})$}

The microtomography scans were carried out at the BL20XU beam line at SPring- 8 on various sample coupons extracted from different stages of the processing of AA 7075. In 
order to extract the sample coupons from the tensile tested coupons, firstly fracture surface of the broken halves of the tensile specimen was covered by cold mounting. Fine precision slicing using slow cutparallel to the load axis of the sample was then applied to generate the coupon containing the fracture surface of the tested specimen. The coupon was then mounted using a double sided tape and manually ground on a 1200 grit paper on opposite and transverse sides to the outer surface. The grinding was periodically interrupted to measure the extent of thickness reduced, until a regular cross-section of nearly $0.6 \times 0.6 \mathrm{~mm}^{2}$ was achieved. The sample coupon thus prepared was cut to a length of $10 \mathrm{~mm}$. The other sample coupons were carefully cut from their respective specimens from regions below the outer surface to a crosssection of nearly $0.6 \times 0.6 \mathrm{~mm}^{2}$ and $10 \mathrm{~mm}$ length.

These sample coupons were scanned in the microtomography set-up at undulator beam line BL20XU consisting of a liquid nitrogen cooled double crystal mono-chromator (Si (111)(111)), diffuser, and a pair of orthogonal slits. A monochromatic beam of energy $20 \mathrm{keV}$ illuminated the sample placed on a precision rotation stage. The projection data recorded by an image detector system, placed $55 \mathrm{~mm}$ from the sample, consisting of a cooled $4000(\mathrm{H}) \times 2624$ (V) element CCD camera (effective pixel size of the camera: $5.9 \mu \mathrm{m}$, used in 2 x 2 binning mode), a LSO:Ce scintillator $\left(\mathrm{Lu}_{2} \mathrm{SiO}_{5}: \mathrm{Ce}\right)$ and a relay lens $(\times 20)$. In total, 1500 radiographs, scanning 180 degrees, were obtained in 0.12-degree increments. The exposure time for a single shot was $30 \mathrm{~ms}$. The resolution of this projection-type SR- $\mu \mathrm{CT}$ set-up is approximately $1 \mu \mathrm{m}$, which is determined primarily by image blurring caused by the Fresnel diffraction, the diffraction limit of visible light and the spatial resolution of a scintillator [26]. Isotropic voxels (a volume element in 3D space) with $0.5 \mu \mathrm{m}$ edges were achieved in the reconstructed slices, that were at least necessary to achieve the $1 \mu \mathrm{m}$ spatial resolution [26, 27]. A convolution back projection algorithm was used for achieving the reconstruction into 16 bit slice dataset. For the purpose of quantitative analysis these 16 bit slice datasets were converted into 8 bit grey scale 
slice dataset using a mapping of the linear attenuation coefficient in the range $0-40 \mathrm{~cm}^{-1}$. The volume rendering in $3 \mathrm{D}$ of the 8 bit reconstructed images obtained from the microtomography scans and its subsequent processing was carried out using VGSTUDIO MAX. The quantitative analysis of the dataset has been carried out by custom software that implemented the marching cube algorithm. The features of each of the objects such as volume, surface area and sphericity along with its centre of mass have been evaluated in the region of interest.

\section{Results}

\subsection{D Visualization.}

Typical 2D slicesin the various datasets derived from tomography scans of different sample coupons corresponding to various conditions given in figure 1 are shown in figure 2 (a) to (e).In all the slices three regions can be distinguished by their grey scale intensity range. The alloy matrix is depicted as grey in all the images. The grey matrix is seen to embed numerous dark and bright objects of different shaped in these slices. The bright shaped objects in the slices are intermetallic particles (containing $\mathrm{Fe}, \mathrm{Cu}$ and $\mathrm{Al}$ ) typically found in the AA7075 and the dark shaped objects are the different types of micro-damage. These dark shaped objects considered as micro-damage are distinguished by a prominent halo at the edges arising from the deflection contrast occurring at the interfaces with the alloy matrix. Intermetallic particles with lower X-ray attenuation coefficient as compared with the alloy matrix such as $\mathrm{Mg}_{2} \mathrm{Si}$ were not considered to be present in the matrix because of the long high temperature solutionising treatment above $500^{\circ} \mathrm{C}$ given to obtain an equiaxed microstructure. At these high solutionising temperatures the $\mathrm{Mg}_{2} \mathrm{Si}$ particles dissolve quickly within minutes [28]. The presence of $\mathrm{Mg}_{2} \mathrm{Si}$ are detected by micro-CT carried out on underaged AA 7075 after giving short term solutionising treatment below $500^{\circ} \mathrm{C}$ which appear as irregular shaped objects with grey regions without an edge enhanced contrast in the 2D slice dataset [29]. The orientation of the particles in the slices is observed to be along columns parallel to the original extrusion 
direction. The dark region outside the boundaries of the grey Al-matrix is air. It is to be mentioned here that apart from the inter-metallic particles, the under-aged microstructure also has sub-micrometer particles typically of $\mathrm{MgZn}_{2}$ type, which has been characterized by Nguyen et. al. [30] for AA7075 alloy subjected to different aging treatments. As the under-age treatment employed by Nguyen et. al. [30] was identical to that employed in the present work submicrometer characterization of the particles was not carried out. The part of the fracture surface seen in slices from the extracted from intergranularly failed samples show typical undulating feature (Fig $2(\mathrm{~d}, \mathrm{e}))$. Fine intergranular cracks are observed to emanate from the fracture surface into the matrix below. The bright Fe-bearing particles located near the fracture surface are observed to be cracked. The slices from uncharged and charged sample both show pores of elliptical and acicular morphology.

The $3 \mathrm{D}$ visualizations of the various datasets are shown in figure 3 . In the renderings of the respective datasets the particles and damage in the matrix have been segmented and represented as aqua and red colours respectively. It is seen from the $3 \mathrm{D}$ volume visualizations of the datasets that the $\Delta_{\mathrm{UC}}^{\mathrm{o}}$ and $\Delta_{\mathrm{C}}^{\mathrm{o}}$ datasets contain well distributed particles and pores. Contrastingly 3D volume visualisations of the datasets $\Delta_{\mathrm{C}}^{\mathrm{T}}, \Delta_{\mathrm{C}}^{\mathrm{F}}: \mathrm{C}$ and $\Delta_{\mathrm{C}}^{\mathrm{F}}: \mathrm{S}$ corresponding to the samples coupons extracted from desorped and deformed and failed samples show that the spatial distribution of micro-damage is in-homogenous in comparison with the particle distribution. The clustering of damage is clearly evident in the 3D volume visualizations of the scanned dataset that contained the intergranular fracture surface i.e. $\Delta_{\mathrm{C}}^{\mathrm{F}}: \mathrm{C}$ and $\Delta_{\mathrm{C}}^{\mathrm{F}}: \mathrm{S}$.

\subsection{Quantitative Analyses}

The quantitative analysis of the various datasets is shown in table 2 . It is seen that the particle content (in terms of volume fraction and number density) in the datasets of $\Delta_{\mathrm{UC}}^{\mathrm{O}}$ and $\Delta_{\mathrm{C}}^{\mathrm{o}}$ is greater than the datasets $\Delta_{\mathrm{C}}^{\mathrm{F}}: \mathrm{C}$ and $\Delta_{\mathrm{C}}^{\mathrm{F}}: \mathrm{S}$. The micro-damage content however is higher only for the datasets $\Delta_{\mathrm{C}}^{\mathrm{O}}$ and $\Delta_{\mathrm{C}}^{\mathrm{F}}$ : S. The trend of the quantitative analyses indicates that the 
effect of hydrogen pre-charging is to increase the micro-damage volume fraction and number density in under-aged AA7075. The effect of desorption, on the other hand, is to reduce the micro-damage content. It is of significance to note that the sample coupons at the centre of the intergranularly failed specimens (i.e. $\Delta_{\mathrm{C}}^{\mathrm{F}}$ : C dataset) contain significantly lower micro-damage fraction and number density compared with that near the surface region (i.e. $\Delta_{\mathrm{C}}^{\mathrm{F}}: \mathrm{S}$ dataset). The average sizes of particle and micro-damage contained in the datasets $\Delta_{\mathrm{C}}^{\mathrm{F}}: \mathrm{C}$ and $\Delta_{\mathrm{C}}^{\mathrm{F}}: \mathrm{S}$ are lower than that in the others. Furthermore the sphericity values of the micro-damage in the datasets $\Delta_{\mathrm{C}}^{\mathrm{F}}: \mathrm{C}$ and $\Delta_{\mathrm{C}}^{\mathrm{F}}: \mathrm{S}$ are lower suggesting that the damage morphology tends to be more acicular shaped than in the other datasets.

The distribution of micro-damage in terms of its number fraction, and volume fraction as a function of size in the various datasets are compared in figure $4(a, b)$ and $5(a-e)$. It is seen that micro-damage size range contained in the datasets $\Delta_{\mathrm{C}}^{\mathrm{F}}: \mathrm{C}$ and $\Delta_{\mathrm{C}}^{\mathrm{F}}: \mathrm{S}$ are significantly higher. Accordingly these datasets derived from sample coupons extracted from specimens that were deformed to fracture after charging are compared separately from those of uncharged, charged and desorped cases. The size distribution of micro-damage is seen to be similarly skewed with the tail of the distribution in all cases starting at $8 \mu \mathrm{m}$. However, the comparison of number density amongst the datasets yields significantly different trends. It is seen from the histogram plot in figure 4 (c) that the number density is maximum in the dataset $\Delta_{\mathrm{C}}^{\mathrm{F}}$ : S followed by the dataset $\Delta_{\mathrm{C}}^{\mathrm{F}}$ : C. In contrast dataset $\Delta_{\mathrm{C}}^{\mathrm{T}}$ shows lower number density values as compared with the datasets $\Delta_{\mathrm{UC}}^{\mathrm{o}}$ and $\Delta_{\mathrm{C}}^{\mathrm{o}}$. Thus the trend of the effect of desorption treatment on the variation of number density is revealed by grouping the datasets $\Delta_{\mathrm{UC}}^{\mathrm{o}}, \Delta_{\mathrm{C}}^{\mathrm{o}}$ and $\Delta_{\mathrm{C}}^{\mathrm{T}}$ (Gr:I datasets). Similarly by grouping the datsets $\Delta_{\mathrm{UC}}^{\mathrm{o}}, \Delta_{\mathrm{C}}^{\mathrm{o}}, \Delta_{\mathrm{C}}^{\mathrm{F}}: \mathrm{C}$ and $\Delta_{\mathrm{C}}^{\mathrm{F}}: \mathrm{S}$ (Gr:II datasets) the influence on the variation of number density as a result of deformation to fracture of the precharged sample is revealed. The variation in the volume fraction due to desorption and deformation to fracture of the precharged samples of underaged AA 7075 is also shown by the 
two dataset groups (figure 5 (a-e)). In the size range 8 to $18 \mu \mathrm{m}$ while the Gr:I datasets show a decreasing trend (figure $5(\mathrm{a}-\mathrm{c})$ ), in case of the Gr:II datasets (figure $5(\mathrm{~d}, \mathrm{e})$ )the volume fraction is nearly constant. In all the datasets the volume fraction increases beyond the micro-damage size range of $18 \mu \mathrm{m}$. Below the size of $8 \mu \mathrm{m}$, the variation in volume fraction is similar for all the datasets in Gr:I. This is not true for the Gr:II datasets where the volume fraction peaks below micro-damage size of $8 \mu \mathrm{m}$ for the deformed datasets $\Delta_{\mathrm{C}}^{\mathrm{F}}: \mathrm{C}$ and $\Delta_{\mathrm{C}}^{\mathrm{F}}: \mathrm{S}$.

The complex distribution of the volume fraction as a function of size is expected to depend on the contributions from different types of micro-damage distributed in the respective size ranges. Two generic types of micro-damage are distinguished to be contained in the datasets based on a damage morphology parameter $(\Omega)$. This parameter is devised to discriminate the shape of the damage on the basis of the volume and surface area which are directly calculated from the tomographic dataset. The ratio of the volume to the surface area quantified for a given damage object in the dataset to its idealized volume equivalent sphere is the basis for the formula used to calculate the $\Omega$ parameter. The formula used for damage morphology parameter $(\Omega)$ is given below:

$$
\Omega=10 \log _{10}\left(\frac{\xi_{\text {ideal }}}{\xi_{\text {actual }}}\right)
$$

where, $\xi_{\text {ideal }}=$ volume to surface area of ideal sphere of given size, $\xi_{\text {actual }}=$ actual volume to surface area of the damage of the same given size.

The morphological description of the damage object using the $\Omega$ parameter provides a conservative approach to distinguish between pores and cracks over a wide size range. The basic criterion used in the study to classify cracks from pores present in the various datasets is fixed to have at least $\Omega$ parameter value of 7 . This value is used as it implies that the cracks have an actual volume to area ratio one fifth that of its idealized sphere, which is similar to the approach adopted by Williams et. al. [31] on the basis of minimum and maximum dimensions 
of the sphere fitted to the given damage contained in ceramics. Furthermore the morphology of the pores is classified as ellipsoid or a cicular based on a respective $\Omega$ parameter value greater or less than 2.5. Using $\Omega$ parameter as the morphological parameter and damage size, the micro-damage content is further subdivided into micro-pore (small ellipsoidal $=\mu \mathrm{E}$ :sPore; large ellipsoidal $=\mu \mathrm{E}:$ LPore; small acicular $=\mu \mathrm{A}:$ sPore; large acicular $=\mu \mathrm{A}:$ LPore $)$ as well as micro-cracks (small $=\mu \mathrm{s}:$ Crack; large $=\mu \mathrm{L}:$ Crack and very large $=\mu \mathrm{XL}:$ Crack $)$ in the different datasets.

The distribution of the various types of damage in the different datasets is depicted in the scatter plot between $\Omega$ parameter and micro-damage size in figure 5 (a-e). It is seen from the scatter diagram that as the damage size increases there is a tendency for the corresponding $\Omega$ parameter to increase for all datasets. Assuming a linear correlation between the two, the strength of the proportional relationship between $\Omega$ parameter and damage size is determined from slope of the linear fit to the scatter diagram for each dataset. The slope of the fitted linear equation to the respective diagrams is determined to be $0.379,0.61,0.559,0.353$, and 0.386 for the datasets $\Delta_{\mathrm{UC}}^{\mathrm{o}}, \Delta_{\mathrm{C}}^{\mathrm{o}}, \Delta_{\mathrm{C}}^{\mathrm{T}}, \Delta_{\mathrm{C}}^{\mathrm{F}}: \mathrm{C}$ and $\Delta_{\mathrm{C}}^{\mathrm{F}}: \mathrm{S}$ respectively. It is thus seen that the Gr:I datasets show an significantly greater increase in slope as compared with the Gr:II datasets. This thus implies that desorption treatment of precharged sample results in the formation of large sized micro-pores with acicular morphology in comparison to straining to fracture after hydrogen charging. As a result the large size micro-pores with ellipsoidal morphology are mainly found in the deformed datasets. Otherwise the increase in the $\Omega$ DMP parameter with size in uncharged, charged and the desorped datasets results in the micro-damage to be mainly constituted of acicular pores and cracks.

The relative contributions to volume fractions from the different types of micro-damage present in the various datasets are depicted as histogram plots in figure 6 (a-e). It is seen that the contribution to the total volume fraction of large sized micro-damage systematically goes 
up in the Gr:I datasets to a level greater than the small sized ones. In the Gr:II datasets however the small sized micro-damage consisting of ellipsoidal and acicular pores and cracks are greater in terms of the proportion of the total micro-damage volume fraction. This increase of the small sized $(<8 \mu \mathrm{m})$ micro-damage volume fraction in the Gr:II datasets is due to the increase in the ellipsoidal shaped pores at the surface and acicular shaped pores at the central regions. Therefore in Gr:II datasets while the ratio of the acicular to the ellipsoidal constituents of small sized pores : $\mu \mathrm{A}:$ sPore and $\mu \mathrm{E}:$ sPore slightly increases from 0.78 to 0.86 for the dataset $\Delta_{\mathrm{UC}}^{\mathrm{o}}$, $\Delta_{\mathrm{C}}^{\mathrm{o}}$, respectively, it falls to about 0.6 for the dataset $\Delta_{\mathrm{C}}^{\mathrm{F}}: \mathrm{S}$ and for dataset $\Delta_{\mathrm{C}}^{\mathrm{F}}: \mathrm{C}$ significantly increases to 1.44. On the contrary this ratio for the Gr:I dataset after desorption show a dramatic increase to 2.1. It is also evident from the histograms of figure 6 (a-e) that the microcrack content systematically increases is greater in the Gr:II than the Gr:I datasets due to the significant increase of the $\mu \mathrm{XL}$ :Crack volume content in the dataset $\Delta_{\mathrm{C}}^{\mathrm{F}}$ : S as compared with the dataset $\Delta_{\mathrm{C}}^{\mathrm{T}}$.

\subsection{Micro-damage Spatial Architecture}

The micro-damage spatial architecture is depicted in terms of their distribution using image intensity maps that plot the number of micro-pores occurring in local unit volumes. For this purpose the coronal slices of the various datasets are divided equally into zones of $20 \mathrm{x} 20 \mu \mathrm{m}^{2}$ and length equal to the respective region thickness. The number of pores in each of the zone is mapped and represented in the image intensity format. Figure 7 shows a comparison between the spatial intensity maps of the various datasets considered in the study. It is clearly seen that in Gr:I datasets there is no tendency for agglomeration of the micro-pores except for the $\Delta_{C}^{T}$ dataset where small dispersed agglomerations can be seen. In contrast in the Gr:II datasets $\Delta_{\mathrm{C}}^{\mathrm{F}}: \mathrm{C}$ and $\Delta_{\mathrm{C}}^{\mathrm{F}}: \mathrm{S}$ there is dramatic difference in the spatial arrangement of micro-pores. In both the datasets characterizing the surface and centre region of the intergranularly failed tensile sample the spatial architecture can be distinguished by strong agglomerations of micro-pores. 
The regions where these agglomerations take place are in close proximity to fine intergranular cracks connected to the fracture surface and outer surface of the sample.

In order to quantify the degree of agglomeration depicted in the intensity map format of the different datasets, a probability approach is adopted. The probability $\mathrm{P}^{\mathrm{ag}}$ that $\mathrm{N}_{\mathrm{ag}}$ micro-pores agglomerate in a given sub-volume in the intensity map follows the relationship given below:

$$
\mathrm{P}^{\mathrm{ag}}=\mathrm{P}_{\mathrm{o}}^{\mathrm{ag}} \mathrm{e}^{-\lambda \mathrm{N}_{\mathrm{ag}}}
$$

where, $\mathrm{P}_{\mathrm{o}}^{\mathrm{ag}}=$ probability that the sub-volume contains at least one micro-pore, $\lambda=$ agglomeration intensity parameter, $\mathrm{N}_{\mathrm{ag}}=$ number of micro-pores in the sub-volume. Agglomeration is defined to be when the sub-volume contains at least one micro-pore. Hence it can be easily shown that $\mathrm{P}_{\mathrm{o}}^{\mathrm{ag}}=\mathrm{e}^{\lambda}$ when $\mathrm{N}_{\mathrm{ag}}=1$. It follows that the agglomeration intensity parameter is computed as $\lambda=\left(1 /\left(1-N_{a g}\right)\right) \ln P^{a g}$. Accordingly for each of the datasets the agglomeration intensity parameter $(\lambda)$ is computed and plotted with the respective total microdamage volume fraction in figure 8 . The Gr:I and Gr:II datasets are separately plotted in figure 8 , from which the distinctly different behaviour of the respective dataset groups are clearly evident. The uncharged dataset where the agglomeration is found to be negligible has value of $\lambda \sim 1$ indicating that the sub-volumes in its intensity map have nearly equal probability to contain more than one micro-pore. After charging the $\lambda$ value of the dataset $\Delta_{C}^{0}$ significantly increases along with the total micro-damage fraction. However on imparting desorption treatment, the total micro-damage fraction in the dataset $\Delta_{C}^{\mathrm{T}}$ significantly decreases with only slight increase in agglomeration intensity parameter. Thus it can be considered that in the Gr:I datasets the decrease of the micro-damage fraction from dataset $\Delta_{C}^{o}$ to $\Delta_{C}^{\mathrm{T}}$ limits any significant increase of agglomeration intensity. The Gr:II dataset group displays the trend that despite a similar decrease in micro-damage fraction from dataset $\Delta_{\mathrm{C}}^{\mathrm{o}}$ to $\Delta_{\mathrm{C}}^{\mathrm{F}}$ : $\mathrm{C}$ the increase of agglomeration intensity parameter is greater than that of dataset characterized after desorption i.e. from dataset $\Delta_{C}^{\mathrm{O}}$ to $\Delta_{\mathrm{C}}^{\mathrm{T}}$. Finally, figure 8 shows that the dataset $\Delta_{\mathrm{C}}^{\mathrm{F}}$ : $\mathrm{S}$ having significantly 
larger micro-damage content than dataset $\Delta_{C}^{0}$ after charging also shows the maximum agglomeration intensity parameter value.

\section{Discussion}

The work establishes for the first time the state of the micro-damage in high strength aluminium alloy due to hydrogen redistribution induced by thermal treatment and deformation using 3-D tomographic datasets. Accordingly the datasets analyzed were divided into two groups, one that constituted the scans from coupons extracted from uncharged, charged and desorped specimens (Gr:I) and the other consisting of the tomographic characterization of coupons extracted from uncharged, charged, deformed specimens at the surface and central regions (Gr:II). In order to assure of hydrogen redistribution as a result of deformation, regions close to the intergranularly failed fracture surface were selected. This is because it is known that rapid hydrogen egress occurs from a precharged tensile specimen at the instance of its fracture in aluminium alloys and steels $[19,21,32]$. This systematic comparison amongst the series of datasets enabled an assessment of the evolution of the damage state not only as a result of charging, but also prior to and after hydrogen redistribution in AA 7075 alloy in the underaged condition.

The comparative evaluation reveals that the state of damage undergoes significant changes after hydrogen redistribution in terms of micro-damage content, morphology and spatial architecture. The micro-damage content (i.e. volume fraction and number density) after charging decreases as the hydrogen desorps out of the material, after the application of thermal treatment. However the micro-damage content is found to increase as a result of deformation at the outer surface of the intergranularly failed tensile specimen. Considering the limited diffusivity of the hydrogen [20] in aluminium alloys and steep concentration gradients [33] that prevails during electrochemical charging, it is expected that the central regions of the tensile specimen would be only be exposed to redistributing hydrogen during deformation and fracture. 
Thus one could consider that state of initial damage state in the tensile sample after charging at the surface to be similar to charged dataset of Gr:I (i.e. $\Delta_{\mathrm{C}}^{0}$ dataset)and that at the centre to be similar to uncharged dataset (i.e. $\Delta_{\mathrm{UC}}^{\mathrm{o}}$ dataset). This would explain the trend of the results obtained regarding the lower damage content, in the central regions of the sample underneath the intergranular fracture surface. However the spatial intensity map of these two regions shows that they have very similar spatial distribution of micro-pores. In both the central and surface regions micro-damage agglomerations near intergranular cracks are seen. Furthermore it is observed that the agglomerated intensity parameter increases by the same amount of $\sim 1.38$ for both the centre and surface after deformation datasets from their likely configurations before test (i.e. corresponding to $\Delta_{\mathrm{UC}}^{\mathrm{o}}$ and $\Delta_{\mathrm{C}}^{0}$ respectively. In the light of these trends it is unequivocally concluded that, although the overall micro-damage content is different, there is convergence in their spatial architecture at the surface and centre regions.

The deformation led enhancement of micro-damage, can be caused by the presence of necking which is practically non-existent in the embrittled tensile specimen. This is because in the failed tensile sample the embrittlement effects are manifested strongly as the intergranular failure mode pervades the fracture surface. Quantitative tomographic analyses reveal that the micro-cracks in datasets $\Delta_{\mathrm{C}}^{\mathrm{F}}: \mathrm{C}$ and $\Delta_{\mathrm{C}}^{\mathrm{F}}: \mathrm{S}$ are too small in size and number to exert their triaxial stress field in a large region of the matrix volume taken for tomographic scan of the surface.

The presence of macroscopic inhomogenous stress state conditions along the specimen diameter such as the presence of a distinctive neck or a large crack in the pre-charged tensile sample would have resulted in rapid increase in micro-damage at the centre of the sample. However the quantitative results point to the fact the total micro-damage content is lower at the centre than at the surface after intergranular failure of the pre-charged tensile specimen. The component of micro-damage that increased at the centre in comparison to the surface after 
deformation is the content of small pores having acicular morphology. The $\mu \mathrm{A}$ :sPore content in percentage terms of the volume fraction of micro-damage in the respective dataset increased to $32 \%$ at the centre as compared with $18 \%$ at the surface. Here it is to be pointed out that these values of the $\mu \mathrm{A}$ :sPore content in the datasets $\Delta_{\mathrm{C}}^{\mathrm{F}}: \mathrm{C}$ and $\Delta_{\mathrm{C}}^{\mathrm{F}}: \mathrm{S}$ are nearly same as the datasets $\Delta_{\mathrm{C}}^{\mathrm{T}}$ and $\Delta_{\mathrm{C}}^{\mathrm{O}}$ respectively. This observation supports the view that the centre region of the precharged tensile sample with an initial micro-damage state similar to the uncharged specimen transitions to a state similar to that of the desorped sample after straining to fracture. The microdamage state due to desorption treatment of the precharged sample is caused by the thermally induced H-detrapping. Therefore it could be concluded that the transitions of the damage state in the central and surface regions of the tensile specimen after intergranular fracture are also influenced by deformation led hydrogen redistribution. It is to be considered that the two regions, the surface and centre regions of the intergranularly failed tensile sample are thousands of micro-meters apart, with possibly different hydrogen contents before deformation. Thus these remarkable similarities in the micro-damage architecture in the two regions provides a strong evidence that the cause of the observed extended agglomerated damage structures are primarily influenced by hydrogen redistribution.

The occurrence of hydrogen redistribution during deformation in precharged materials is ubiquitous precursor step in the manifestation of hydrogen embrittlement in aluminium alloys [19]. This redistribution of hydrogen is inevitably associated with dislocation motion [34]. It is, therefore, more likely that dislocations and its interaction with hydrogen have important role in the formation of agglomerated damage state. Furthermore the presence of the latter near intergranular cracks indicates that an in-homogenous local spatial plastic deformation could trigger such a state of agglomeration by preferentially enhancing both dislocation density and hydrogen content. The interaction of the dislocations with hydrogen in aluminium matrix results in two opposing tendencies. The basic effect of enhanced hydrogen 
is to increase the dislocation mobility, observed from in-situ TEM studies [35, 36]. However in aluminium, the presence of interstitial hydrogen in matrix introduce a lattice contraction [35] which provides a rationale for the increase in vacancy concentration [37,38] and the formation of H-vacancy complexes [38]. Apart from increase in mobility of dislocations, the presence of hydrogen induces slip planarity $[30,36]$ which is explained by either a decrease in stacking fault energy [36] or enhanced dislocation shielding [39]. Assuming that some of the hydrogen exists as H-vacancy complexes, a non-uniform shielding of the dislocations constrained to move in given plane along with other obstacles such as dislocation - dislocation interaction could occur. This could likely lead to the formation of elastic stress centres consisting of a cluster of H-vacancy complex.

A configuration where dislocation would not be uniformly shielded implies that increasing deformation would, therefore, be accommodated in 'soft' zones where intense plastification takes place (because shielding is relatively higher and slip is planar). and Consequently the pining points that arise from interaction of $\mathrm{H}$-vacancy complex clusters and dislocations, and the self-interaction of the latter, would experience high local stress. This transient bifurcation of stress is accommodated by the creation of damage (in terms of pores and voids)and point defects (such as vacancies). In hydrogen precharged matrix there is evidence for increase in lattice defects [40 - 43] as well as damage [38, 43] under the influence of deformation. Furthermore it has been s'hown by that in low alloy steels hydrogen promotes void growth at low tri-axiality levels [44]. Thus during deformation as the internal cracks attract dislocations, the presence of high levels of hydrogen localizes the dislocation motion and exacerbates the damage formation and growth in their immediate vicinity. It needs to be pointed out that the regions of operation of these processes are relatively far from the crack tip (tens of micrometers) where degradation processes such as onset of lattice instability via high vacancy concentration [45] or ligament instability via high void density [46] are expected to 
operate. This is consistent with the interpretations of Shih et. al. [47] and Robertson et. al. [48], that plasticity occurs not at the boundaries that lie in the crack path but in their close vicinity [39].

The spatial proximity of the extended agglomerated regions to intergranular cracks emanating from the fracture surface or the specimen outer surface edge of a deforming a precharged material could play a mechanistic role in manifestation of hydrogen embritttlement. It has been shown in the study that the desorption treatment to reduce the hydrogen content in the material results in increase of the pore agglomeration in the matrix. As a result a reduction of the manifestation of embrittlement in pure aluminium is observed [49]. In pure Iron and Inconel 625 desorption of hydrogen by appropriate annealing prior to testing nearly reverses the loss of ductility (Takai et. al [40]). This beneficial effect is manifested in iron and Inconel 625 , even if annealing treatment is given after prestraining the charged specimen. Thus it can be considered that presence of localized hydrogen - free agglomerated regions distributed within the matrix in the desorped dataset is relatively benign to the development of intergranular cracks.

The deformation after precharging also results in release of hydrogen in materials (eg. Steels and Inconel ) $[40,41,50]$. However, as pointed out that the presence of intergranular cracks connected to the surface would attract the redistributing hydrogen. This is because they as they-would not only provide a free surface for hydrogen to assume its lowest energy configuration but also would provide a pathway of egress out of the sample. Thus, in the precharged aluminium alloy the redistribution of hydrogen would be directed towards existing incipient intergranular cracks where formation of extended agglomerated micro-pore structure in close proximity occurs possibly from accommodation of transient stresses arising from localization of plasticity. To explore the possibility that whether the hydrogen repartitions to these micro-pores it is worthwhile to explore the relationship of fraction of micro-pores sites 
in the total available trapping sites as a function of the agglomerated intensity parameter. A proportional relationship between the two parameters would strengthen the argument that extended agglomerated regions are likely to trap and repartition the redistributed hydrogen during deformation, as the micro-pores contained in them have been shown to act as strong trap sites in Al-Si alloy [24]. Accordingly the total trap sites of each type for the datasets under study is calculated and summarized in table 3 (Detailed calculations given in supplementary material). The plot between the fraction of micro-pores to the total available trap sites and the agglomeration intensity parameter is shown in figure 9 . The plot indeed shows a positive linear relationship between the agglomeration intensity parameter and the micro-pore trap site fraction. The increase of the trap site fraction in the total available trap sites for the datasets can be arranged in the ascending order as : $\Delta_{\mathrm{UC}}^{\mathrm{o}}, \Delta_{\mathrm{C}}^{\mathrm{o}} \Delta_{\mathrm{C}}^{\mathrm{T}}, \Delta_{\mathrm{C}}^{\mathrm{F}}: \mathrm{C}$ and $\Delta_{\mathrm{C}}^{\mathrm{F}}: \mathrm{S}$ respectively. Significantly, it is seen that although the agglomeration intensity parameter is increased for the dataset $\Delta_{\mathrm{C}}^{\mathrm{T}}$, the micro-pore trap site fraction is dramatically reduced. This thus implies that embrittlement would be strongly manifested when the matrix provides avenues to retain the redistributing hydrogen such as through its repartition to micro-pores in the agglomerated region. This possibility of a repartition step in the matrix during redistribution of hydrogen under homogenous plastic deformation (i.e. no serrated flow) is supported by the observation of a decrease in release rate until the instance of fracture after peaking at low strains [51].

The results shown in the work provides strong reason to explicitly consider the evolution in the state of micro-damage to elucidate the manifestation of hydrogen embrittlement via intergranular cracking in aluminium alloys. The results show that deformation led redistribution of hydrogen form extended agglomerated regions near intergranular cracks. Although the results do not show if the agglomerated zone forms prior to intergranular cracks (requiring sub-micrometer characterization of damage in matrix at interrupted strain intervals), its presence is shown to be of mechanistic consequence to sustain 
growth of cracks by its proclivity to trap hydrogen. Hence the understanding of hydrogen embrittlement in aluminium alloys would be served by a multiscale mechanism where the governing physics of atomistic scale interactions of hydrogen are facilitated by concurrent damage evolution in the nano- (eg. voids / vacancies [40,52,53] and micro- scale (eg. micropores).

\section{Conclusions}

The following conclusions are established from the evaluation of damage state in hydrogen redistributed regions induced by desorption and deformation in AA 7075 by the application of SR- $\mu$ CT:

1. The hydrogen redistribution by both desorption and deformation results in a significant change in the prevailing state of micro-damage.

2. The basic characteristic of hydrogen redistribution is the tendency to form agglomerated structures in the matrix.

3. The unique damage state in hydrogen induced brittle failure in underaged AA7075 is shown to be composed of extended agglomerated structures in the vicinity of the intergranular cracks possibly from the tendency for plastic localisation.

4. It is shown that the state of damage is benign for the case of hydrogen redistribution caused by desorption due to a decrease in the micropore fraction of the trap sites in the matrix. Contrastingly the configuration of extended agglomerated structures in the vicinity of intergranular cracks is shown to increase the fraction of micropore sites for repartition of hydrogen. Hence this damage state is considered to be of a mechanistic consequence to manifest hydrogen embrittlement in underaged AA 7075.

\section{Acknowledgements}

CG gratefully acknowledges Japan Society for Promotion of Science (JSPS) for the JSPS 
fellowship award and the grant-in-aid for scientific research (No. 22.00384) that enabled the research work to be carried out Toyohashi University of Technology. The synchrotron radiation experiments were performed with the approval of JASRI (Proposal No. 2011B1164). CG thankfully acknowledges all relevant staff at SPring-8, Japan for the support during beam-time.

\section{References}

1. D.E.J. Talbott, Effects of hydrogen in aluminium, magnesium, copper and their alloys, .Int. Metall. Rev. 20 (1975) 166 - 184.

2. M. Leger, G. R. Piercy, Internal friction in hydrogen charged aluminium alloys Philos. Mag. A 43 (1981) $377-390$.

3. R.P.Gangloff, Hydrogen assisted cracking of high strength alloys in: Milne I, Ritchie RO, Karihalo O (eds) Comprehensive Structural Integrity Vol 6, New York :Elsevier Publishing, 2003.

4. S. P. Lynch, Environmentally assisted cracking : Overview of evidence for an adsorption - induced localized - slip process, Acta. Metall. 36 (1988) 2639 - 2661.

5. L. Christodoulou, H. M. Flower, Hydrogen embrittlement and trapping in Al-6\%-Zn-3\%Mg, Acta. Metall. 28 (1980) 481 - 487.

6. I. M. Robertson, D. Lillig, Ferreira PJ, Revealing the fundamental process controlling hydrogen embritlement in: Sonnerday. B, Sofronis P, Jones R (eds) Effects of hydrogen on Materials.

7. R. A. Oriani, Hydrogen - The versatile embrittlerCorrosion 43 (1987) 390 - 397.

8. M O Speidel, Stress corrosion cracking of aluminium alloys, Metall. Trans. 6A (1975) 661 -665 .

9. G. A. Young JR, J. R. Scully, The diffusion and trapping of hydrogen in high purity aluminium, Acta. Mater. 46 (1998) 6337 - 6349.

10. S. W. Smith, J. R. Scully, The identification of hydrogen trapping states in an Al-Li-Cu-Zr alloy using thermal desortion spectroscopy, Metall. Mater. Trans 31A (2000) 179 - 193.

11. R. G. Song, M. K. Tseng, B. J. Zhang, J. Liu, Z. H. Jin, K. S. Shin, Grain boundary segregation and hydrogen induced fracture in 7050 aluminium alloy, Acta. Mater. 44 (1996) $3241-3248$.

12. G. M. Bond, I. M. Robertson, H. K. Birnbaum, The influence of hydrogen on deformation and fracture process in high-strength aluminium alloys, Acta. Mater. 35 (1987) 2289 2296. 
13. J. K Park, A. J. Ardell, Effect of retrogression and re-aging treatments on the microstructure of Ai-7075-T651, Metall. Met. Trans, 15A (1984) 1531-1543.

14. J. Albrecht, A. W. Thompson, I M Bernstein, The role of microstructure in hydrogen assisted fracture of 7075 aluminium, Metall. Trans. 10A (1979) 1759-1766.

15. K. Rajan, W. Wallace, J. C. Beddoes, Microstructural study of a high strength stress corrosion resistant 7075 aluminium alloy 17 (1982) 2817-2824.

16. H. Kamoutsi, G N Haidemenopoulos, V Bontozoglou, S Pantelakis, Corrosion induced hydrogen embrittlement in aluminium alloy 2024, Corros. Sci. 48 (2006) 1209-1224.

17. Y. Deng, Z. yin, K. Zhao, J. Duan, J. Hu, Z. He, Effects of Sc and Zr micro-alloying additions and aging time at $120 \mathrm{C}$ on corrosion behaviour of a Al-Zn-Mg alloy, Corros. Sci. 54 (2012) 288-298.

18. H C Fang, K H Chen, X Chen, H Chao, G S Peng, Effect of Cr, Yb and Zr additions on localized corrosion of Al-Zn-Mg-Cu alloy, Corros. Sci. 51 (2009) 2872-2877.

19. J. A. Donovan, Accelerated evolution of hydrogen from metals during plastic deformation, Metall. Trans. 7A (1976) $1677-1683$.

20. N. Takano, Hydrogen diffusion and embrittlement in 7075 aluminium alloy, Mater. Sci. Eng. A, 483-84 (2008) 336 - 339.

21. G. Itoh, T. Jinkoji, M. Kanno, K. Koyama, Effect of impurity hydrogen on the deformation and fracture in an Al-5 mass Pct Mg alloy, Metall. Mater. Trans. 28A (1997) 2291 - 2295.

22. M. Taheri, J. Albrecht, I. M. Bernstein, A. W. Thompson, strain rate effects on hydrogen embrittlement of 7075 aluminium, Scripta. Metall. 13 (1979) 871-875.

23. R. G. Song, M. K. Tseng, B. J. Zhang, J. Liu, Z. H. Jin, K. S. Shin, Grain boundary segregation and hydrogen - induced fracture in 7050 aluminium alloy, Acta. Mater. 44 (1996) $3241-3248$.

24. H Toda, T Hidaka, M Kobayashi, K Uesugi, A takeuchi, K Horikawa. Growth behaviour of hydrogen micropores in aluminium alloys during high-temperature exposure, Acta. Mater. 57 (2009) 2277-2290.

25. G M Scamans, Discontinuous propagation of stress corrosion cracks in Al-Zn-Mg alloys, Scr. Metall. 13 (1979) 245 -249.

26. A Takeuchi, K Uesugi, H Takano, Y Suzuki, Sub-micrometre resolution three dimensional imaging with hard X-ray imaging microtomography, Rev. Sci. Instrum., 2002; 73: 42464250 .

27. D Seo, F Tomizato, H Toda, K Uesugi, A Takeuchi, Y Suzuki, M Kobayashi, Spatial resolution of synchrotron x-ray microtomography in high energy range : Effect of x-ray 
energy and sample to detector distance, Appl. Phys. Lett. 101 (2012) 261901.

28. X. Zang, M. Guo, J. Zhang, L. Zhuang, Dissolution of precipitated during solution treatment ofAl-Mg-Si-Cu alloys. Metall. Mater. Trans 47B (2016) 608-620.

29. S. S. Singh, J. J. Williams, T. J. Stanned, X. Xiao, F. D. Carlo, N Chawla, Measurement of local corrosion rates at inclusion particles in AA7075 by in-situ three dimensional (3D) Xray synchrotron tomography, Corros. Sci. 104 (2016) 330-335.

30. D Nguyen, A W Thompson, I M Bernstein, Microstructural effects on hydrogen embrittlement in a high purity 7075 aluminium alloy, Acta. Mater. 35 (1987) 2417-2425.

31. J J Williams, Z Flom, A AAmell, N Chawla, X Xiao, F De Carlo, Damage evolution in SiC particle reinforced alloy matrix composites by X-ray synchrotron tomography, 58 (2010) $6194-6205$.

32. H. Toda, H. Oogo, K Horikawa, K Uesugi, A Takeuchi, Y Suzuki, M Nakazawa, Y Aoki, M Kobayashi, The true origin of ductile fracture in aluminium alloys Metall. Mater. Trans 45A (2014) 765-776.

33. J. T. Burns, R. P. Gangloff,Effect of low temperature on fatigue crack formation and microstructure - scale growth from corrosion damage in $\mathrm{Al}-\mathrm{Zn}-\mathrm{Mg}-\mathrm{Cu}$, Metall. Mater. Trans. 44A(2013) 2083-2105.

34. J. K. Tien, A. W. Thompson, I. M. Bernstein, R. J. Richards, Hydrogen transport by dislocations, Metall. Trans. 7A (1976) 821 - 829.

35. G. M. Bond, I. M. Robertson, H. K. Birnbaum, Effects of hydrogen on deformation and fracture process in high purity aluminium, Acta. Metall. 36 (1988) $2193-2197$.

36. P. J. Ferriera, I. M. Robertson, H. K. Birnbaum, Hydrogen effects on the interaction between dislocations, Acta. Metall. 46 (1998) 1749-1757.

37. H. K. Birnbaum, C. Buckley, F. Zeides, E. Sirois, P. Rozenak, S. Spooner, J. S. Lin, Hydrogen in aluminium, J. Alloy. Comp. 253-254 (1997) 260-264.

38. P. Rozenak, States of hydrogen and deuterium in chemically charged high purity aluminium, J. Alloy. Comp. 587 (2014) 800-806.

39. H. K. Birnbaum, P. Sofronis, Hydrogen enhanced localized plasticity - a mechanism for hydrogen related fracture, Mater. Sci. Eng. A176 (1994) 191 - 202.

40. K. Takai, H. Shoda, H. Suzuki, M. Nagumo, Lattice defects dominating hydrogen-related failure of metals, Acta. Mater. 56 (2008) 5158 - 5167.

41. M. Nagumo, K. Takai, N. Okuda, Nature of hydrogen trapping sites in steels induced by plastic deformation, Jour. Alloy. Comp. 293-295 (1999) 310 - 316.

42. K. Sakaki, T. Kawase, M. Hirato, M. Mizuno, H. Araki, Y. shirai, N. Nagumo, The effect 
of hydrogen on vacancy generation in iron by plastic deformation, Scripta. Mater. 55 (2006) $1031-1034$.

43. J. H. Ryu, Y. S. Chun, C. S. Lee, H. K. D. H. Bhadeshia, D W. Suh, Effect of hydrogen trapping and effusion in TRIP - assisted steel Acta. Mater. 60 (2012) 4085 - 4092.

44. M. Dadfarnia, P. Novak, D. C. Ahn, J. B. Liu, P. Sofronis, D. D. Johnson, I . M. Robertson, Recent advances in the study of structural materials compatibility with hydrogen, Adv. Mater. 22 (2010) 1128 - 1135.

45. R. W. Cahn, Crystal defects and melting, Nature 273 (1978) 491 - 492.

46. A. Needleman, V. Tvergaard, An analysis of ductile rupture modes at a crack tip, J. Mech. Phys. Solid. 35 (1987) $151-190$.

47. D. Shih, I. M. Robertson, H. K. Birnbaum, Hydrogen embrittlement of $\alpha$ titatnium: In situ studies, Acta. Metall. 36 (1988) $111-124$.

48. I. M. Robertson, T. Tabata, W. Wei, F. Heubaum, H. K. Birnbaum, Hydrogen embrittlement and grain boundary fracture, Scripta. Metall. 18 (1984) $841-846$.

49. H. Suzuki, D. Kobayashi, N. Hanada, K. Takai,, Y. Hagihara, Existing state of hydrogen in electrochemically charged commercial purity aluminium and its effects on tensile properties, Mater. Trans. 52 (2011) 1741 - 1747.

50. H. Shoda, H. Suzuki, K. Takai, Y. Hagihara, Hydrogen desorption behaviour of pure iron and inconel 625 during elastic and plastic deformation, ISIJ Inter. 50 (2010) 115 - 123.

51. K. Horikawa, H. Yamada, H. Kobayashi, Effect of strain rate on hydrogen gas evolution behaviour during tensile deformation in 6061 and 7075 aluminium alloys, Jap. Inst. Light. Metals, 62 (2012) $306-312$.

52. M. Nagumo, Hydrogen related failure of steels - a new aspect, Mater. Sci Technol. 20 (2004) $940-950$.

53. J. Song, W. A. Curtin, A nanoscale mechanism of hydrogen embrittlement in metals, Acta. Mater. 59 (2011) $1557-1569$.

Table 1: Chemical composition of the AA 7075 used for the investigations

\begin{tabular}{|c|c|c|c|c|c|c|c|c|c|}
\hline $\mathrm{Si}$ & $\mathrm{Fe}$ & $\mathrm{Cu}$ & $\mathrm{Mn}$ & $\mathrm{Mg}$ & $\mathrm{Cr}$ & $\mathrm{Zn}$ & $\mathrm{Ti}$ & $\mathrm{Zr}+\mathrm{Ti}$ & $\mathrm{Al}$ \\
\hline$<0.40$ & $<0.50$ & 1.6 & $<0.30$ & 2.5 & 0.23 & 5.6 & $<0.20$ & $<0.25$ & bal. \\
\hline
\end{tabular}




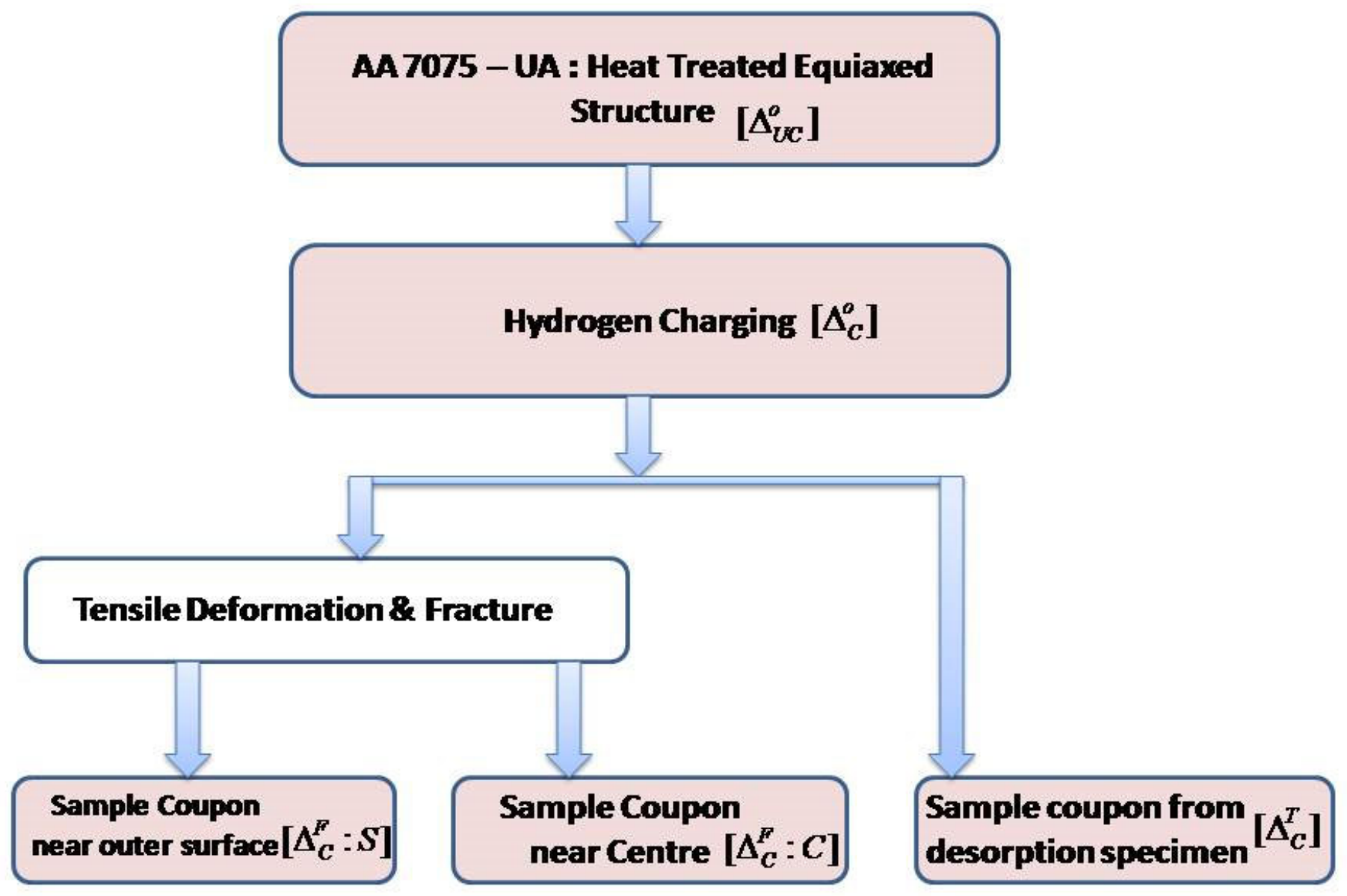

Figure 1.The history of processing of the sample coupons subjected to tomographic studies (in colour background). The nomenclature for the individual dataset obtained by scanning each of the sample coupons subjected to the various processing conditions is given alongside. 

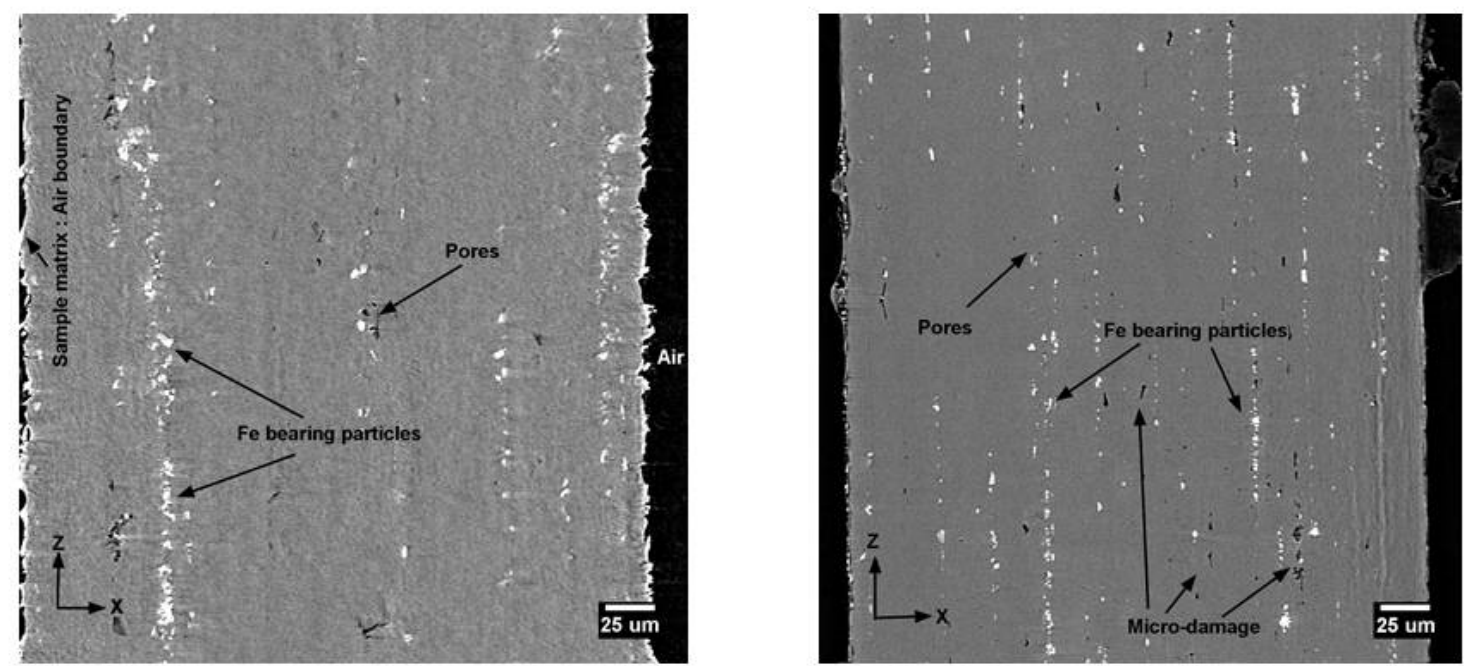

(a)

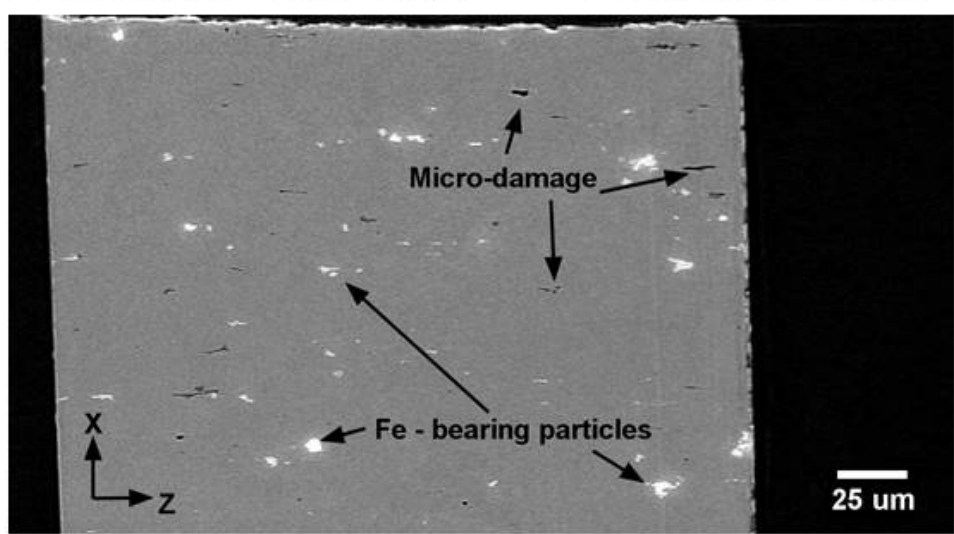

(b)

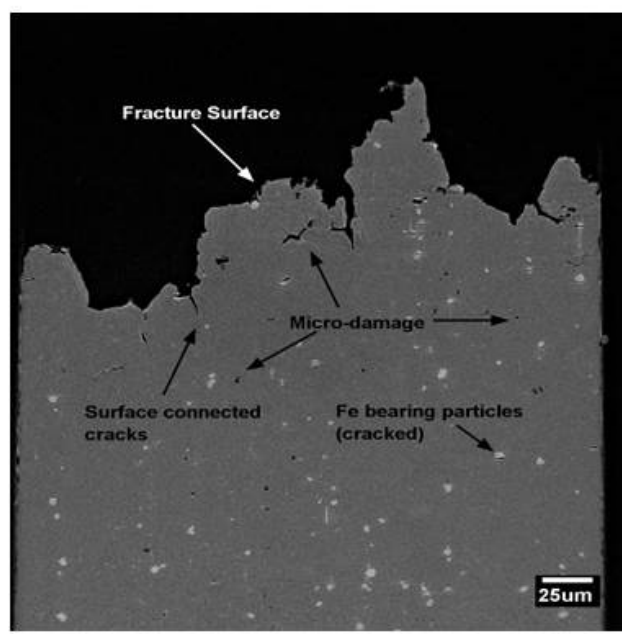

(d)

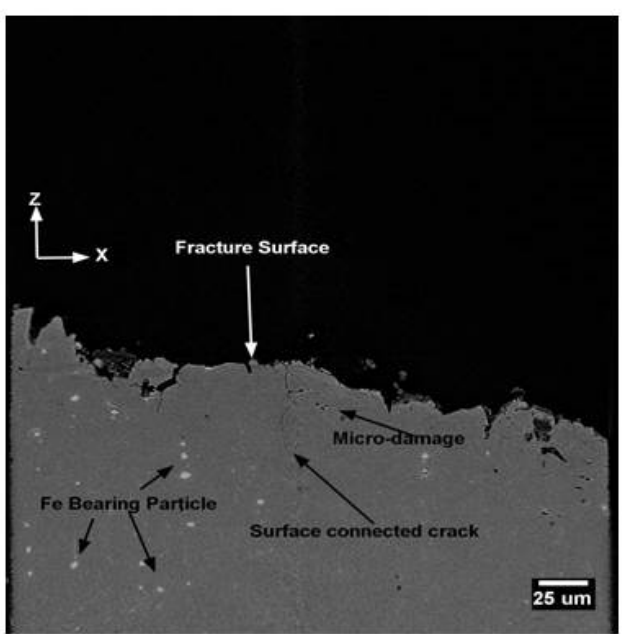

(e)

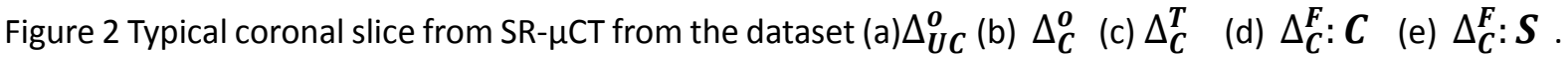
The slices containing the representative Fe-bearing particles, cracks and different forms of micro-damage in the individual datasets are also shown. 

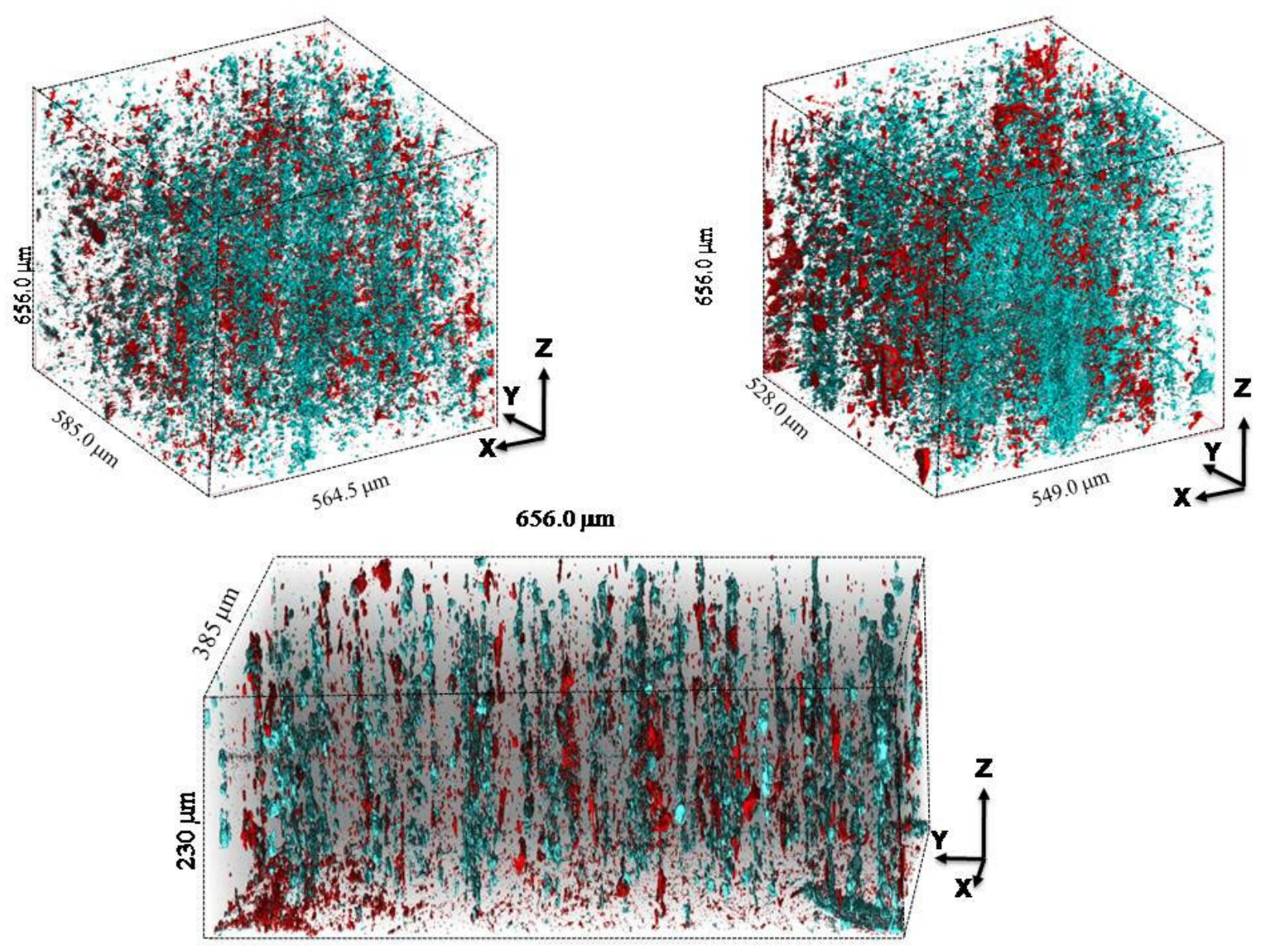

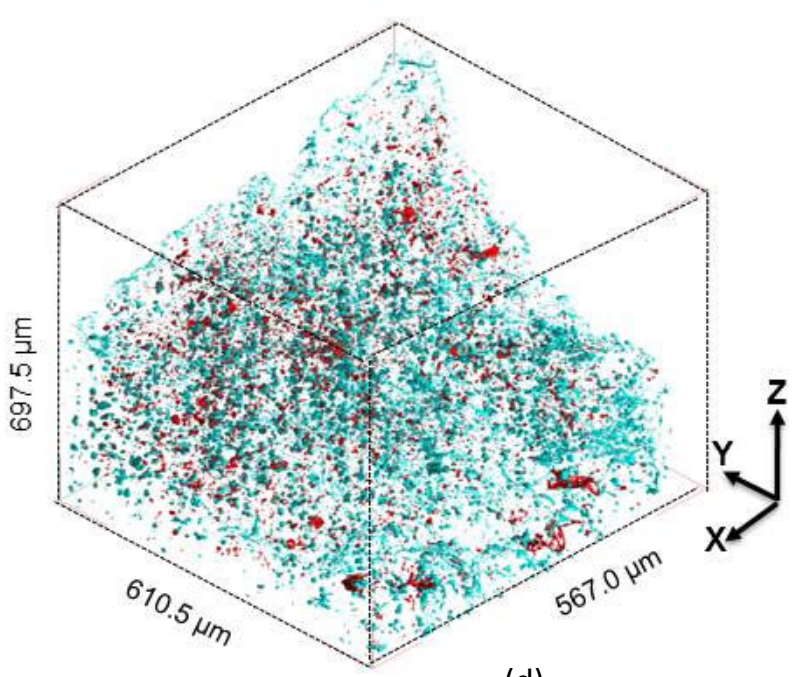

(d)

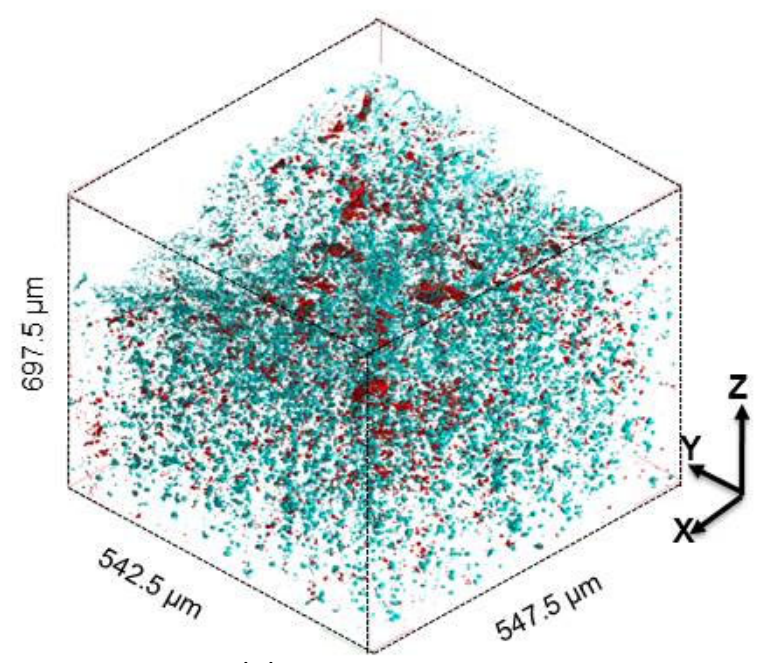

(e)

Figure 3. 3D visualization of the volume scanned using microtomography showing the internal segmented volume of the various datasets containing particles (aqua), pores/voids (red) and cracks (yellow). The datasets are (a) $\Delta_{U C}^{\boldsymbol{O}}$ (Uncharged) (b) $\Delta_{C}^{\boldsymbol{O}}$ (Charged) (c) $\Delta_{C}^{T}$ (Desorped) (d) $\Delta_{C}^{F}$ : $\boldsymbol{C}$ (Deformed extracted from centre region) (e) $\Delta_{C}^{F}: S$ (Deformed and extracted from surface region) .The Z-axis represents the direction of extrusion. 
Table 2: 3D characteristics of the micro-damage and particles in the various datasets

\begin{tabular}{|c|c|c|c|c|c|}
\hline \multirow[t]{2}{*}{ 3D Parameter } & \multicolumn{5}{|c|}{ Micro-damage in datasets } \\
\hline & $\Delta_{U C}^{o}$ & $\Delta_{C}^{0}$ & $\Delta_{C}^{T}$ & $\Delta_{C}^{F}: C$ & $\Delta_{C}^{F}: S$ \\
\hline Volume Fraction (\%) & 0.18 & 0.28 & 0.14 & 0.13 & 0.31 \\
\hline $\begin{array}{c}\text { Number Density } / \mathrm{m}^{3} \\
10^{12}\end{array}$ & 45.3 & 61.2 & 31.6 & 37.7 & 71.2 \\
\hline $\operatorname{Size}(\mu \mathrm{m})$ & 4.2 & 4.4 & 4.4 & 3.3 & 3.2 \\
\hline Sphericity & 0.35 & 0.39 & 0.29 & 0.25 & 0.31 \\
\hline \multirow[t]{2}{*}{ 3D Parameter } & \multicolumn{5}{|c|}{ Particle in datasets } \\
\hline & $\Delta_{U C}^{o}$ & $\Delta_{C}^{o}$ & $\Delta_{C}^{T}$ & $\Delta_{C}^{F}: C$ & $\Delta_{C}^{F}: S$ \\
\hline Volume Fraction (\%) & 0.91 & 1.02 & 0.4 & 0.34 & 0.33 \\
\hline $\begin{array}{c}\text { Number Density } / \mathrm{m}^{3} \\
10^{12}\end{array}$ & $\begin{array}{c}113 . \\
4\end{array}$ & 147.5 & 56.2 & 67.6 & 70.4 \\
\hline $\operatorname{Size}(\mu \mathrm{m})$ & 5.2 & 5.1 & 5.1 & 3.7 & 3.6 \\
\hline Sphericity & 0.37 & 0.39 & 0.27 & 0.24 & 0.24 \\
\hline
\end{tabular}

$\Delta_{U C}^{o}$ : Uncharged dataset; $\Delta_{C}^{o}$ : Charged dataset; $\Delta_{C}^{T}$ : Desorption dataset; $\Delta_{C}^{F}: C$ : Deformed dataset from centre of the intergranularly failed sample; $\Delta_{\mathrm{C}}^{\mathrm{F}}: \mathrm{S}:$ Deformed dataset from centre of the intergranularly failed sample

Table 3 : A comparison of trap sites in the different datasets (Summarized from supplementary material).

\begin{tabular}{|l|c|c|c|c|r|}
\hline Trap Sites (atoms $/ \mathrm{cm}^{3}$ ) & $\Delta_{\boldsymbol{U}}^{\boldsymbol{O}}$ & $\Delta_{\boldsymbol{C}}^{\boldsymbol{O}}$ & $\Delta_{\boldsymbol{C}}^{\boldsymbol{T}}$ & $\Delta_{\boldsymbol{C}}^{\boldsymbol{F}}: \boldsymbol{C}$ & $\Delta_{\boldsymbol{C}}^{\boldsymbol{F}}: \boldsymbol{S}$ \\
\hline Normal interstitial sites & $6.03 \times 10^{22}$ & $6.03 \times 10^{22}$ & $6.03 \times 10^{22}$ & 0.00 & 0.00 \\
\hline intermetallic particles & $1.89 \times 10^{18}$ & $1.93 \times 10^{18}$ & $2.30 \times 10^{17}$ & $7.33 \times 10^{16}$ & $8.38 \times 10^{16}$ \\
\hline Mg atoms & $4.26 \times 10^{22}$ & $4.26 \times 10^{22}$ & $4.26 \times 10^{22}$ & $4.26 \times 10^{22}$ & $4.26 \times 10^{22}$ \\
\hline Dislocations & $3.96 \times 10^{17}$ & $3.96 \times 10^{17}$ & $3.96 \times 10^{17}$ & $8.90 \times 10^{17}$ & $8.90 \times 10^{17}$ \\
\hline Vacancies & $3.43 \times 10^{11}$ & $2.54 \times 10^{20}$ & $3.43 \times 10^{11}$ & $2.54 \times 10^{20}$ & $2.54 \times 10^{20}$ \\
\hline micro-pores & $9.59 \times 10^{16}$ & $1.46 \times 10^{17}$ & $7.65 \times 10^{16}$ & $6.64 \times 10^{16}$ & $8.67 \times 10^{16}$ \\
\hline eta- ppts & $3.89 \times 10^{12}$ & $3.89 \times 10^{12}$ & $3.89 \times 10^{12}$ & $4.82 \times 10^{12}$ & $4.82 \times 10^{12}$ \\
\hline
\end{tabular}

$\Delta_{U C}^{o}$ : Uncharged dataset; $\Delta_{C}^{o}$ : Charged dataset $; \Delta_{C}^{T}$ : Desorption dataset; $\Delta_{C}^{F}: C$ : Deformed dataset from centre of the intergranularly failed sample; $\Delta_{C}^{\mathrm{F}}: \mathrm{S}:$ Deformed dataset from centre of the intergranularly failed sample 


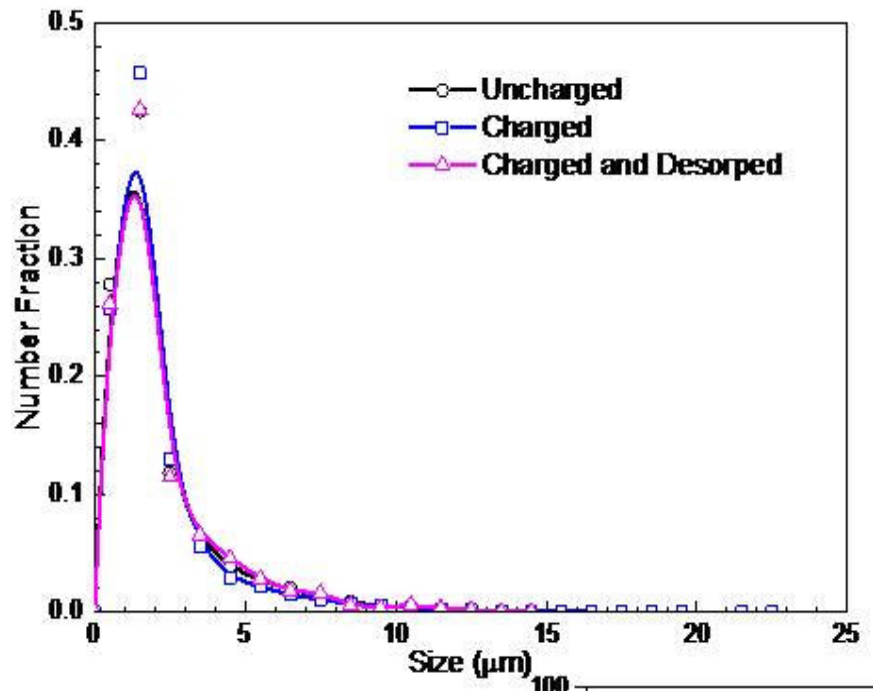

(a)

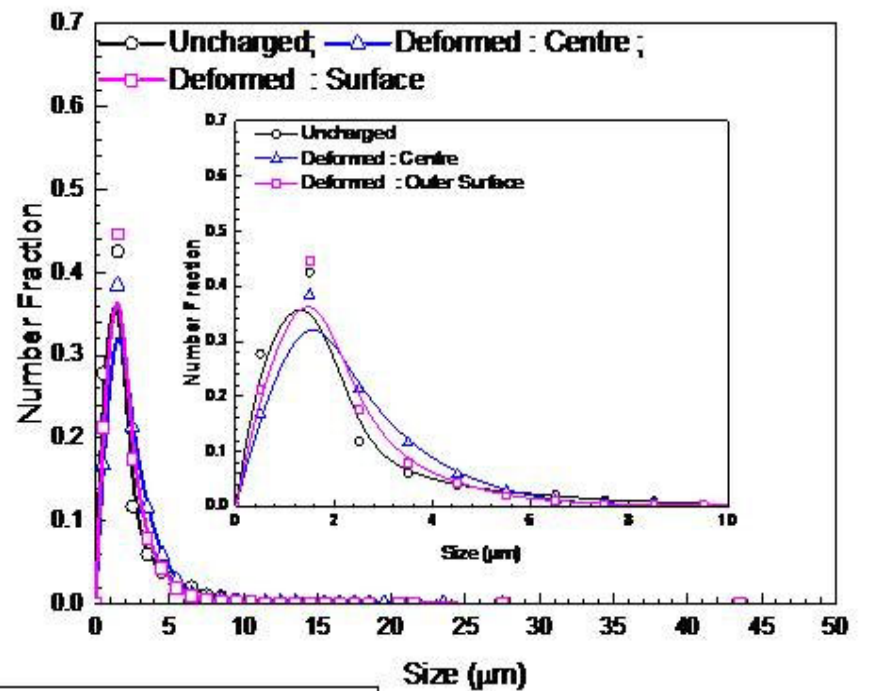

(b)

(c)

Figure 4. Plots showing size distribution of the micro-damage for the datasets representing (a) $\Delta_{U C}^{\boldsymbol{o}}$ (Uncharged) $\Delta_{C}^{\boldsymbol{o}}$ (Charged) ; $\Delta_{C}^{T}$ (Desorped); (b) $\Delta_{C}^{F}: \boldsymbol{C}$ (Deformed extracted from centre region); $\Delta_{C}^{F}: S$ (Deformed and extracted from surface region) $\quad$ (c) Histogram plot of number density determined from quantitative analysis for the above datasets. 

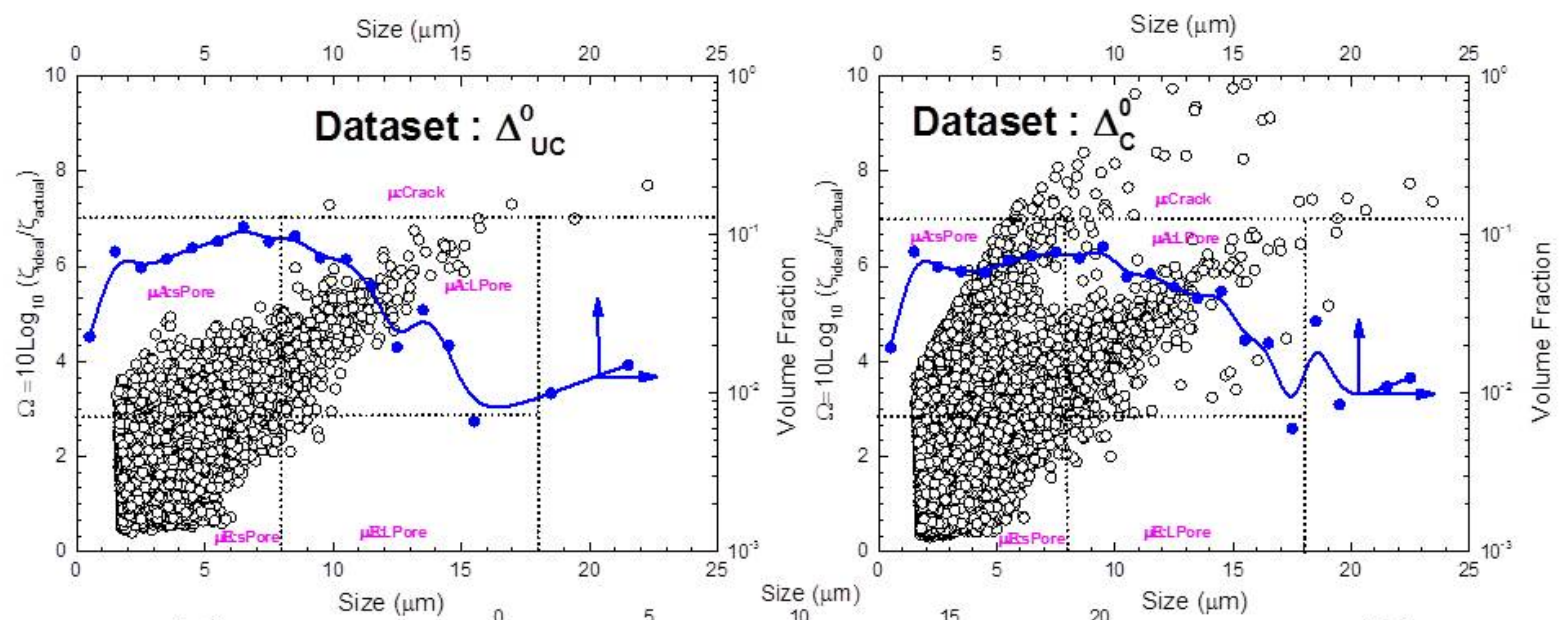

(a)
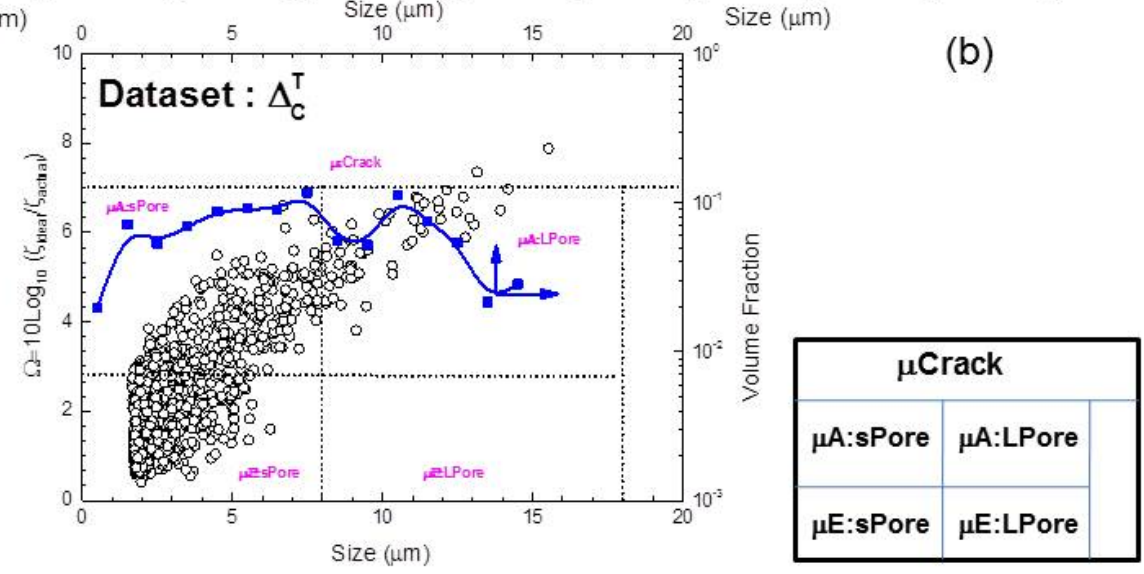

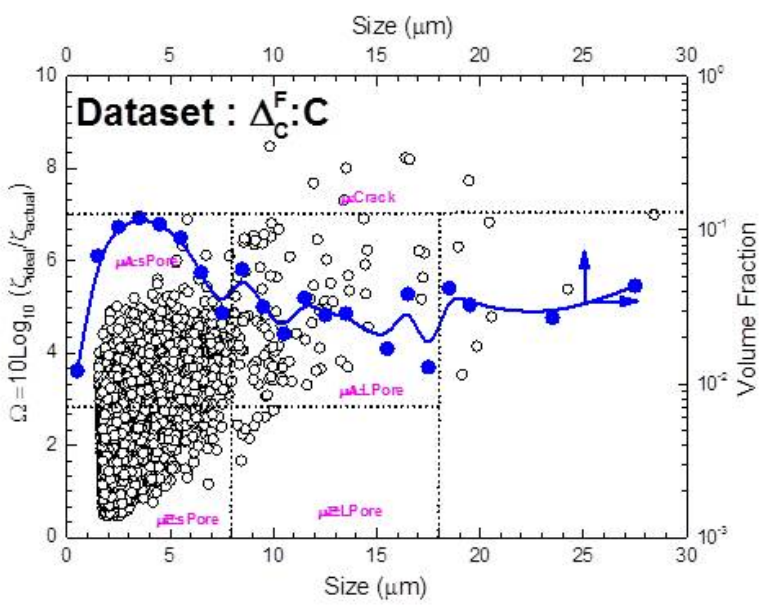

(d)

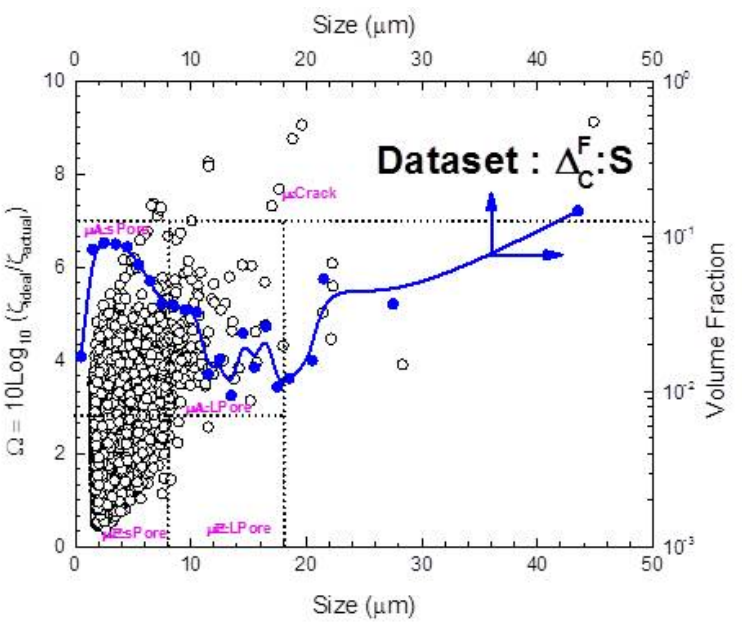

(e)

Figure 5 Plot showing the variation in the volume fraction with micro-damage size determined from the

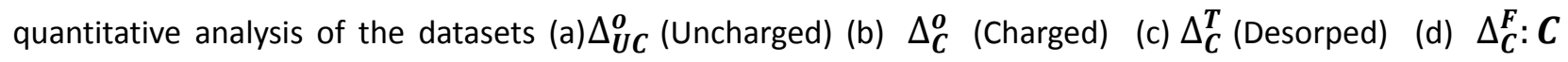
(Deformed extracted from centre region) (e) $\Delta_{C}^{F}: S$ (Deformed and extracted from surface region). A scatter plot of $\Omega$ (DMP) parameter with size is also shown for the respective datasets with the demarcation of the space classifying the various types of micro-damage. The various types of micro-damage are classified as : pores of acicular (which is further divided into small i.e. $\mu \mathrm{A}: s$ Pore and large i.e. $\mu \mathrm{A}:$ LPore) and ellipsoidal morphology (which is further divided into small i.e. $\mu \mathrm{E}: s$ Pore and large i.e. $\mu \mathrm{E}: L P o r e$ ), and cracks (i.e. $\mu$ Cracks). 


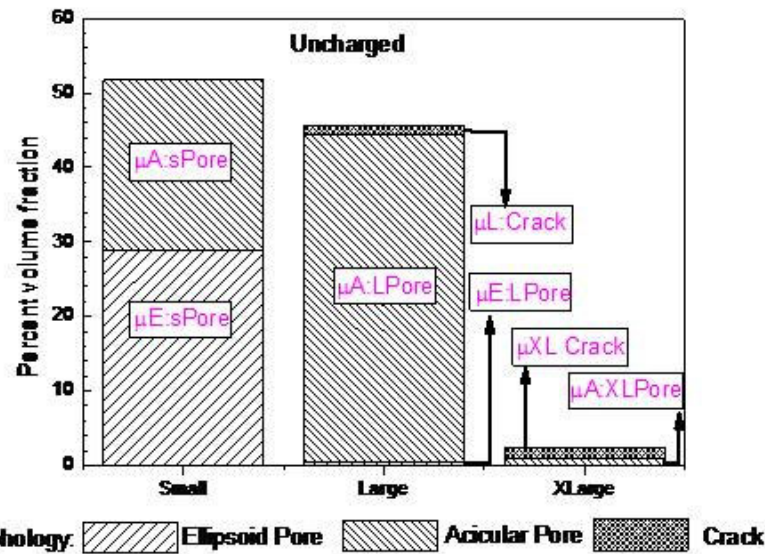

(a)

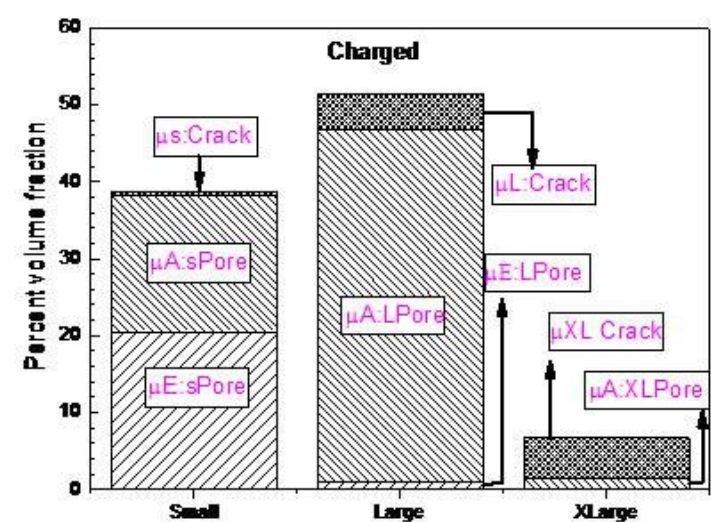

(b)

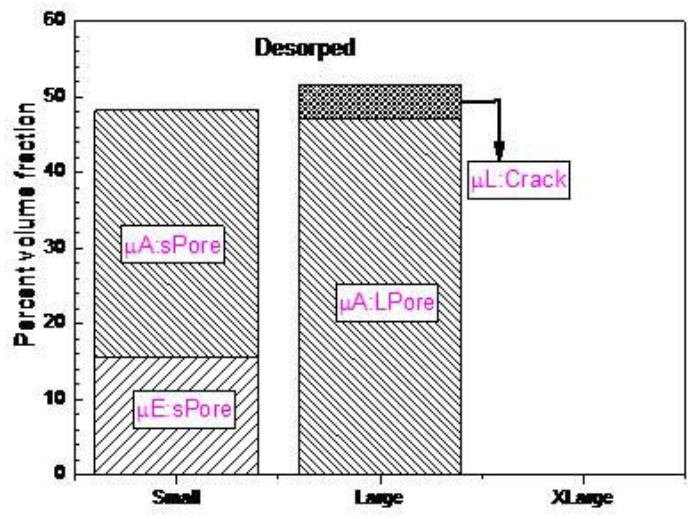

(c)

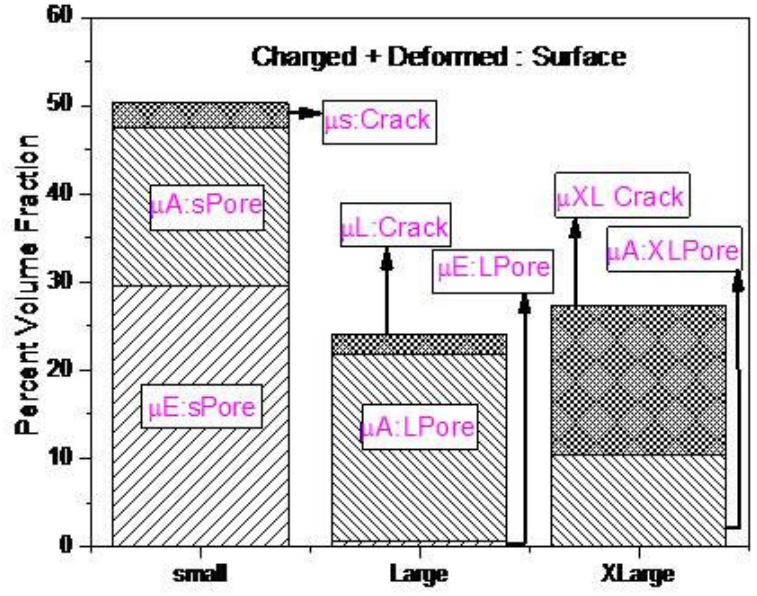

(d)

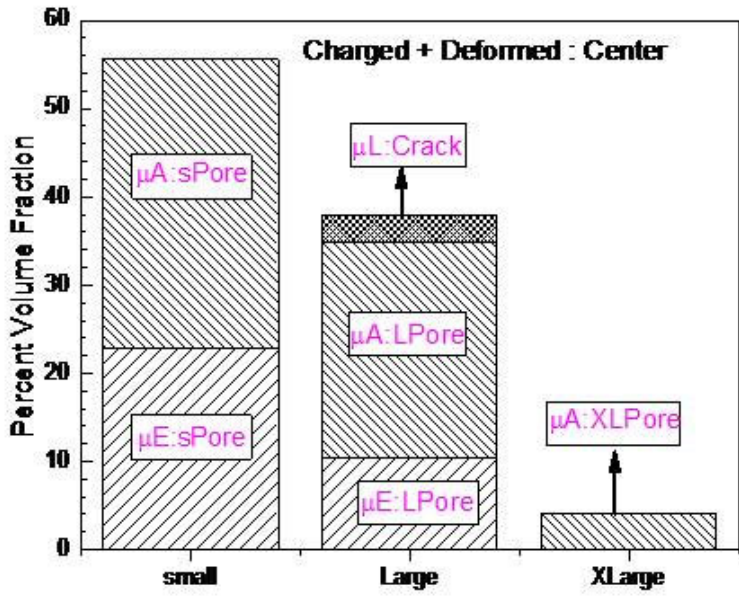

(e)

Figure 6. Histogram plots showing the percent fraction of the total volume contributed by the different types of micro-damage in the datasets (a) $\Delta_{\boldsymbol{U} C}^{\boldsymbol{O}}$ (Uncharged) (b) $\Delta_{\boldsymbol{C}}^{\boldsymbol{O}}$ (Charged) (c) $\Delta_{\boldsymbol{C}}^{\boldsymbol{T}}$ (Desorped) (d) $\Delta_{\boldsymbol{C}}^{\boldsymbol{F}}: \boldsymbol{S}$ (Deformed extracted from surface region) (e) $\Delta_{\boldsymbol{C}}^{\boldsymbol{F}}: \boldsymbol{C}$ (Deformed and extracted from Centre region). The different types of micro-damage are denoted as: $\mu \mathrm{E}: s$ Pore (for small pore of ellipsoidal morphology); $\mu \mathrm{A}: s$ Pore (for small pore of acicular morphology); $\mu \mathrm{E}$ :LPore (for large pore of ellipsoidal morphology); $\mu \mathrm{A}$ :LPore (for large pore of acicular morphology); $\mu$ s:crack (for small crack); $\mu \mathrm{L}$ :Crack (for large crack); $\mu \mathrm{L}:$ Crack (for large crack); $\mu \mathrm{XL}: C r a c k$ (for crack $>18 \mu \mathrm{m}$ ) and $\mu \mathrm{A}: X L P o r e$ (for acicular pore $>18 \mu \mathrm{m}$ ). 


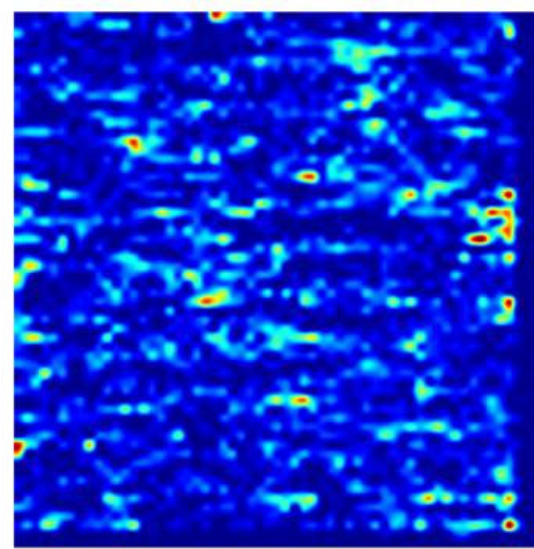

Dataset : $\Delta_{U C}^{\circ}$

(a)
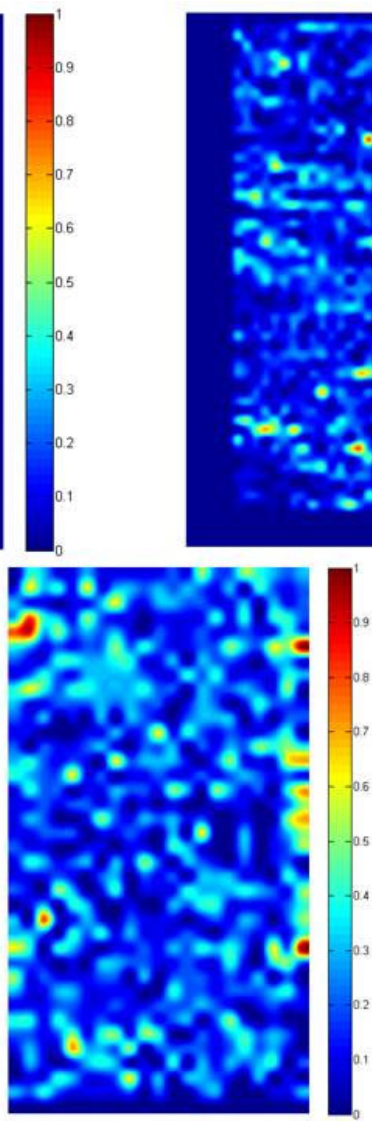

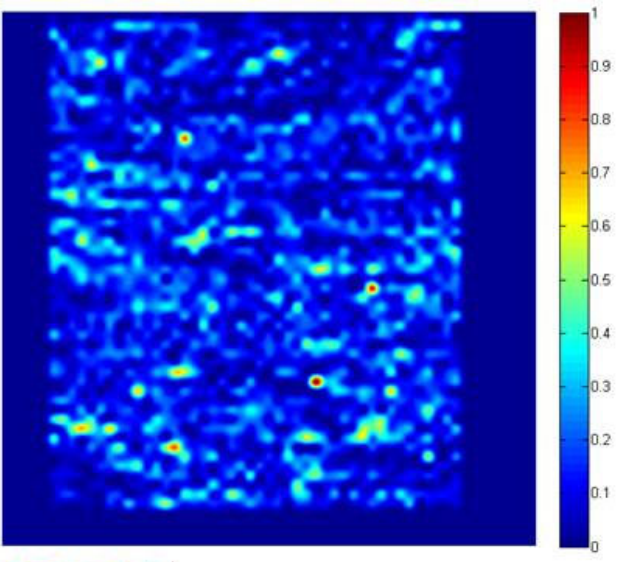

Dataset : $\Delta_{C}^{\circ}$

(b)

\section{Dataset : $\Delta_{C}^{T}$}

(c)

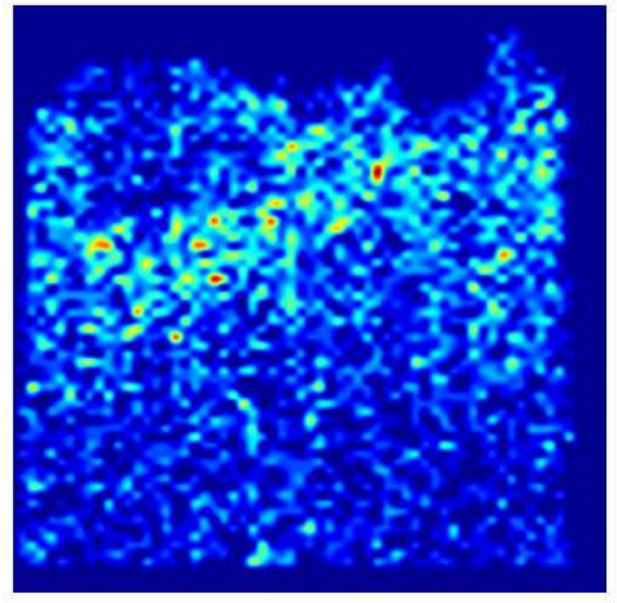

Dataset $: \Delta_{C}^{F}: C$

(d)

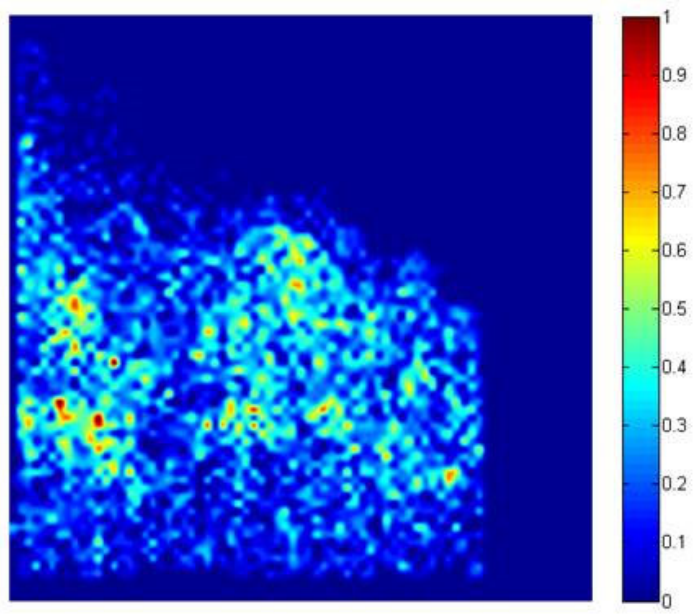

Dataset : $\Delta_{C}^{F}: S$

(e)

Figure 7. The spatial distribution of pores in sub-volume depicted as image intensity maps in the datasets (a) $\Delta_{U C}^{o}$ (Uncharged) (b) $\Delta_{C}^{o}$ (Charged) (c) $\Delta_{C}^{T}$ (Desorped) (d) $\Delta_{C}^{F}: \boldsymbol{C}$ (Deformed and extracted from centre region) (e) $\Delta_{C}^{F}: S$ (Deformed and extracted from surface region). 


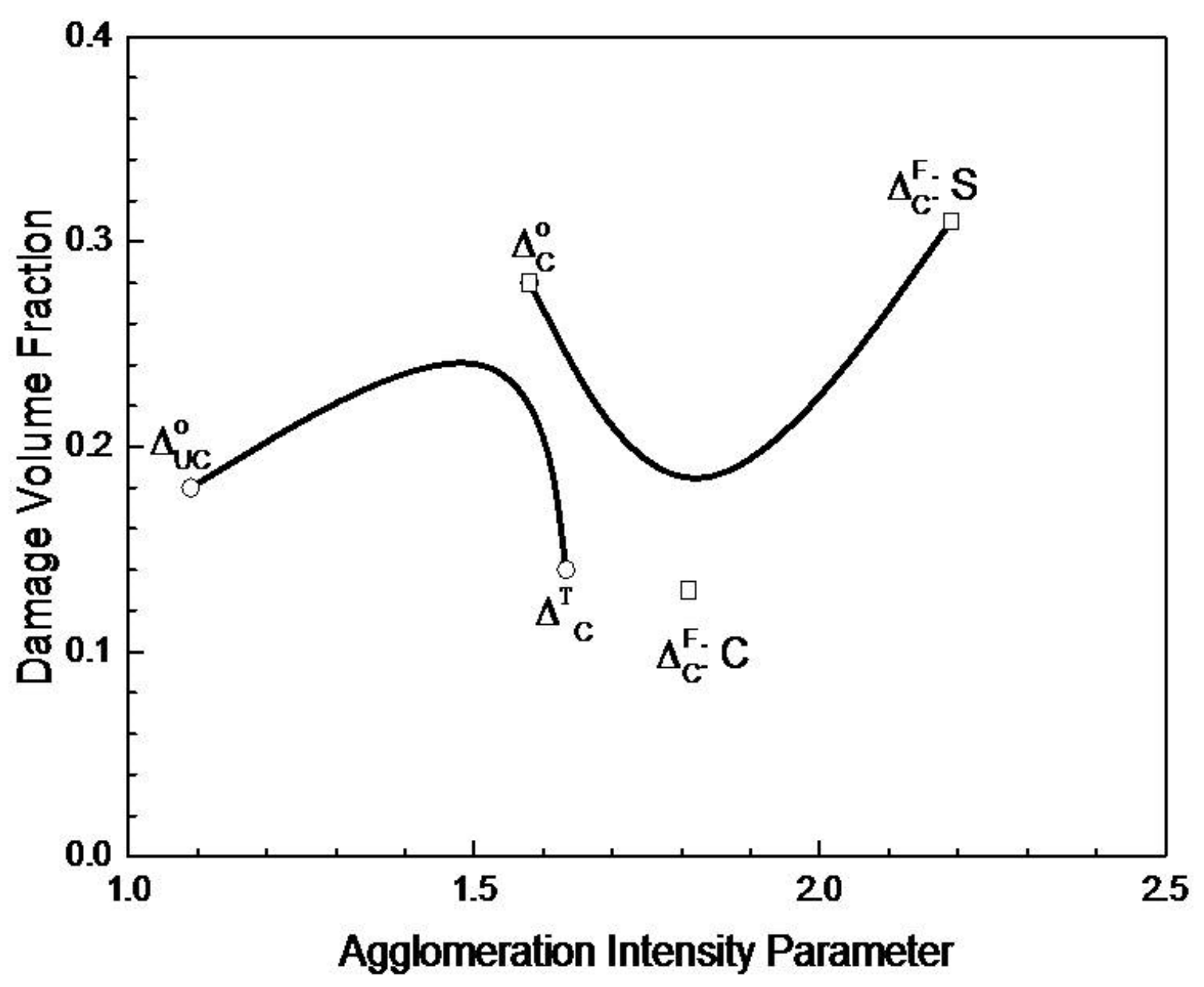

Figure 8. Plot showing the variation of agglomeration intensity parameter for the dataset Gr:I consisting of $\Delta_{U C}^{\boldsymbol{o}}$ (Uncharged); $\Delta_{C}^{\boldsymbol{o}}$ (Charged) ; $\Delta_{C}^{T}$ (Desorped) and Gr:II consisting of regions $\Delta_{C}^{\boldsymbol{o}}$ (Charged); $\Delta_{C}^{F}: \boldsymbol{C}$ (Deformed extracted from centre region) ; $\Delta_{C}^{F}: S$ (Deformed and extracted from surface region). 


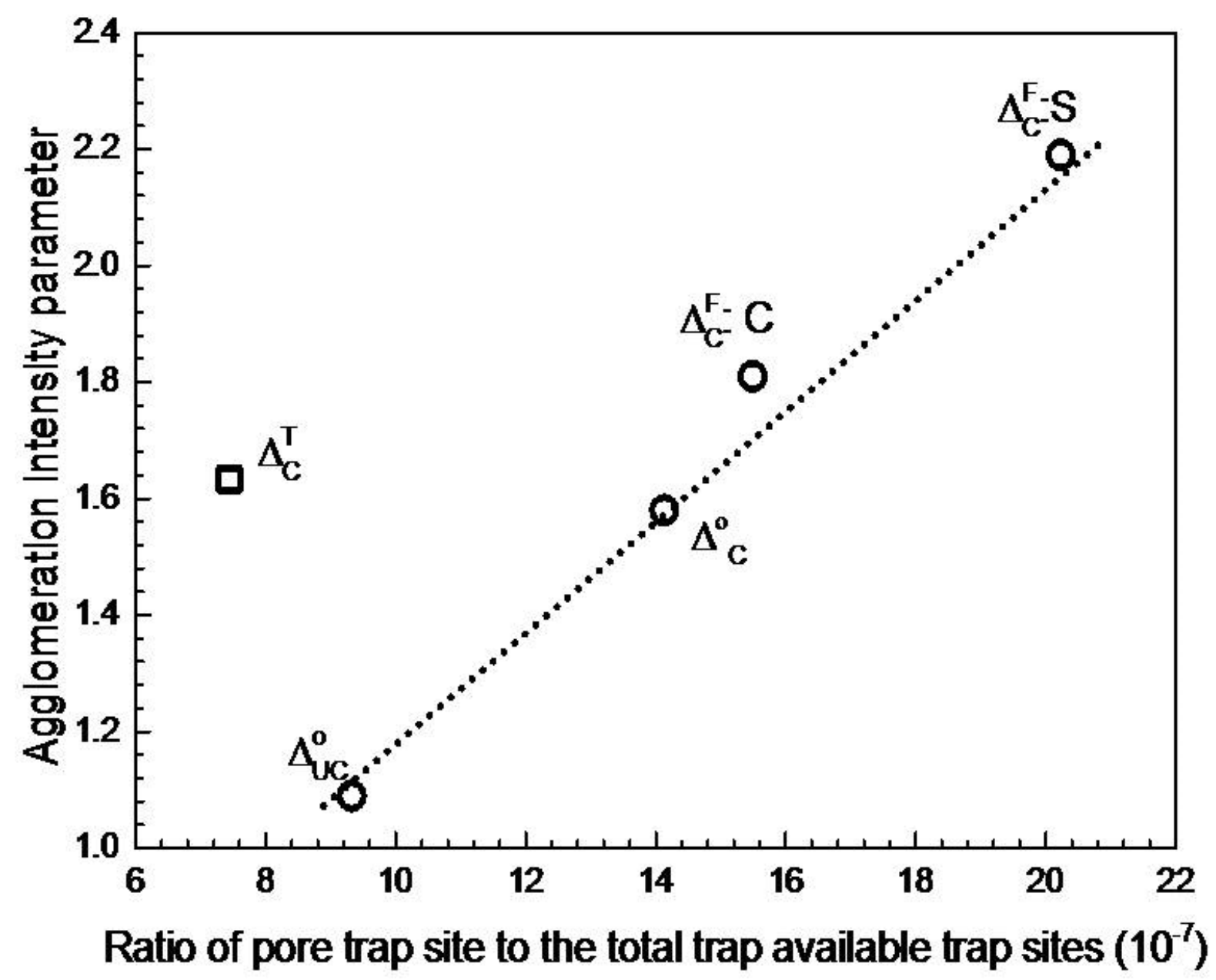

Figure 9. Plot showing the variation of agglomeration intensity parameter with ratio of the pore trap site to the total available trap sites for the datasets $\Delta_{U C}^{o}$ : Uncharged; $\Delta_{C}^{o}$ : Charged; $\Delta_{C}^{T}$ : Desorption; $\Delta_{C}^{F}: C$ : Deformed from centre of the intergranularly failed sample; $\Delta_{C}^{\mathrm{F}}: \mathrm{S}$ : Deformed from centre of the intergranularly failed sample. 